\title{
Modeling and sensitivity analysis of transport and deposition of radionuclides from the Fukushima Dai-ichi accident
}

\author{
X. Hu ${ }^{1,2,3}$, D. Li ${ }^{4}$, H. Huang ${ }^{2}$, S. Shen ${ }^{2}$, and E. Bou-Zeid ${ }^{3}$ \\ ${ }^{1}$ Institute of Police Information Engineering, People's Public Security University of China, Beijing, China \\ ${ }^{2}$ Institute of Public Safety Research, Department of Engineering Physics, Tsinghua University, Beijing, China \\ ${ }^{3}$ Department of Civil and Environmental Engineering, Princeton University, Princeton, New Jersey, USA \\ ${ }^{4}$ Program of Atmospheric and Oceanic Sciences, Princeton University, Princeton, New Jersey, USA
}

Correspondence to: H. Huang (hhong@ mail.tsinghua.edu.cn)

Received: 21 November 2013 - Published in Atmos. Chem. Phys. Discuss.: 23 January 2014

Revised: 25 August 2014 - Accepted: 13 September 2014 - Published: 22 October 2014

\begin{abstract}
The atmospheric transport and ground deposition of radioactive isotopes ${ }^{131} \mathrm{I}$ and ${ }^{137} \mathrm{Cs}$ during and after the Fukushima Dai-ichi Nuclear Power Plant (FDNPP) accident (March 2011) are investigated using the Weather Research and Forecasting-Chemistry (WRF-Chem) model. The aim is to assess the skill of WRF in simulating these processes and the sensitivity of the model's performance to various parameterizations of unresolved physics. The WRF-Chem model is first upgraded by implementing a radioactive decay term into the advection-diffusion solver and adding three parameterizations for dry deposition and two parameterizations for wet deposition. Different microphysics and horizontal turbulent diffusion schemes are then tested for their ability to reproduce observed meteorological conditions. Subsequently, the influence of emission characteristics (including the emission rate, the gas partitioning of ${ }^{131} \mathrm{I}$ and the size distribution of ${ }^{137} \mathrm{Cs}$ ) on the simulated transport and deposition is examined. The results show that the model can predict the wind fields and rainfall realistically and that the ground deposition of the radionuclides can also be captured reasonably well. The modeled precipitation is largely influenced by the microphysics schemes, while the influence of the horizontal diffusion schemes on the wind fields is subtle. However, the ground deposition of radionuclides is sensitive to both horizontal diffusion schemes and microphysical schemes. Wet deposition dominated over dry deposition at most of the observation stations, but not at all locations in the simulated domain. To assess the sensitivity of the total daily deposition to all of the model physics and inputs, the averaged absolute value of the difference (AAD) is proposed. Based on AAD,
\end{abstract}

the total deposition is mainly influenced by the emission rate for both ${ }^{131} \mathrm{I}$ and ${ }^{137} \mathrm{Cs}$; while it is not sensitive to the dry deposition parameterizations since the dry deposition is just a minor fraction of the total deposition. Moreover, for ${ }^{131} \mathrm{I}$, the deposition is moderately sensitive (AAD between 10 and $40 \%$ between different runs) to the microphysics schemes, the horizontal diffusion schemes, gas-partitioning and wet deposition parameterizations. For ${ }^{137} \mathrm{Cs}$, the deposition is very sensitive (AAD exceeding $40 \%$ between different runs) to the microphysics schemes and wet deposition parameterizations, but moderately sensitive to the horizontal diffusion schemes and the size distribution.

\section{Introduction}

Large amounts of radionuclides were released into the atmosphere after the nuclear accident at the Fukushima Dai-ichi Nuclear Power Plant (FDNPP) on 11 March 2011. Later, the Japanese government reported that the radioactive materials were detected in the food and water supply in Fukushima and adjacent areas (Zakaib, 2011). Radionuclides can significantly jeopardize human health, causing cancer and acute radiation diseases (Till and Grogan, 2008). Understanding the spatial and temporal distributions of radionuclides is key to assessing and mitigating the health impact of radioactive releases; it is thus important to be able to accurately model their atmospheric transport and ground deposition.

Over the past few decades, many numerical models have been developed and applied for studying the transport and 
deposition of radionuclides (Andronopoulos and Bartzis, 2010; de Sampaio et al., 2008; Lauritzen et al., 2007; Lutman et al., 2004; Terada and Chino, 2008; Leelossy et al., 2011). For this particular accident at Fukushima, the Community Multi-scale Air Quality (CMAQ) model (Morino et al., 2011), the Lagrangian transport models HYSPLIT and FLEXPART with meteorological conditions provided by the Weather Research and Forecasting (WRF) model (Srinivas et al., 2012), and the WRF-Chem tracer model which directly couples the simulation of the chemistry and meteorology (Huh et al., 2012, 2013) have been used. These studies, together with many previous studies for other events, have identified a number of meteorological variables that can significantly influence the atmospheric transport and ground deposition of radionuclides, including wind and rainfall (Basit et al., 2008; Mathieu et al., 2012; Takemura et al., 2011; Ten Hoeve and Jacobson, 2012; Yamauchi, 2012). For example, the study of Morino et al. (2011) has shown that during the period from 11 to 30 March 2011, the amounts of ${ }^{131}$ I and ${ }^{137} \mathrm{Cs}$ transported across the eastern boundary (downwind) of their domain are $6.52 \times 10^{16} \mathrm{~Bq}$ and $4.58 \times 10^{15} \mathrm{~Bq}$, respectively; while those across the western boundary (upwind) are only $1.49 \times 10^{12} \mathrm{~Bq}$ and $1.13 \times 10^{7} \mathrm{~Bq}$, respectively. This illustrates how wind direction significantly affects the atmospheric transport of radionuclides. Rainfall is another important factor that can influence the ground deposition of radionuclides considerably. Studies of the Fukushima accident report that the estimated deposition mainly occurred when frontal rain bands passed over Japan on 21 March 21 (Yasunari et al., 2011). Deposition of the radionuclides mainly occurred between 15 to 17 and 19 to 21 March, when heavy rainfall was observed, as reported by Srinivas et al. (2012). During these days, wet deposition was significantly higher than dry deposition. Even over longer periods, wet deposition usually still dominates over dry deposition. Given the findings above, it is clear that an accurate simulation of meteorological fields is a necessary condition for the accurate simulation of the transport and deposition of the radionuclides.

As illustrated by Talbot et al. (2012), wind is usually one of the most challenging parameters to simulate successfully. Furthermore, it is also quite difficult to reproduce the spatial and temporal precipitation patterns in numerical models $(\mathrm{Li}$ et al., 2013). However, the previous studies are focused on the behavior of radionuclides with the meteorological conditions simply taken from some numerical weather prediction models or analysis/reanalysis products, without an assessment of whether errors in the radionuclides fate and transport are linked to errors in the meteorological fields or in the transport and decay models.

Emission rate is another critical factor that controls the rate of atmospheric transport and ground deposition of radionuclides (Korsakissok et al., 2013; Morino et al., 2011, 2013). For instance, the study of Korsakissok et al. (2013) reported that the total deposition (sum of dry and wet depo- sition within a certain domain; in this paper, it is used interchangeably with ground deposition) from the Fukushima accident of ${ }^{137} \mathrm{Cs}$ (over land and within $80 \mathrm{~km}$ of FDNPP) is less than $1.5 \times 10^{15} \mathrm{~Bq}$ with the emission rate estimated by (Chino et al., 2011) but more than $5.5 \times 10^{15} \mathrm{~Bq}$ with the emission rate estimated by Stohl et al. (2012). The importance of using accurate estimation of emission source strength has been also demonstrated by the sensitivity analyses of Morino et al. (2013). However, previous studies solely focused on the emission rate, and other emission characteristics such as the gas partitioning of ${ }^{131}$ I were also not considered. The gaseous fraction of ${ }^{131} \mathrm{I}$ was simply set as a constant such as $80 \%$ (Morino et al., 2011) and 2/3 (Korsakissok et al., 2013). A review (Sportisse, 2007) shows that the gaseous fraction varies among different studies: 65 to $80 \%$ (Chamberlain, 1991), 50-65\% (Clark and Smith, 1988), and 70-90\% in Baklanov and Sorensen (2001). This review also points out that the partitioning between gaseous and particulate phases is crucial for capturing the ground deposition of radionuclides. Apart from the gas partitioning, the size distribution of particles is another important characteristic that has not been thoroughly studied, since some deposition schemes explicitly take the size distribution into account (Brandt et al., 2002).

In this study, to address some of the research gaps detailed above, we choose to adopt the WRF-Chem framework (Grell et al., 2005), which provides multiple parameterizations for different unresolved physical processes. WRF-Chem directly couples the forecasting of the chemistry and meteorology, allowing the transport simulations to exploit the full spatial and temporal resolutions of the meteorological simulations. This is expected to yield better results than offline approaches where pre-computed meteorological fields have to be interpolated to drive the chemical transport module. Meteorological fields are however not the only source of uncertainty that can reduce the accuracy of transport and deposition simulations. Previous studies have also shown that different dry and wet deposition parameterizations can cause different deposition rates and accumulated amounts of radionuclides (see e.g., Brandt et al., 2002). In this study, several dry and wet deposition parameterizations are thus also added to the WRFChem model to test and intercompare their performances. Moreover, we consider the emission of ${ }^{131}$ I with different gaseous fractions and that of ${ }^{137} \mathrm{Cs}$ with different particle size distributions. The specific questions this study aims to answer are as follows:

1. What model setup parameters have the largest influence on the simulated meteorological fields and what is the influence of these fields on deposition?

2. What is the relative importance of wet versus dry deposition, and how sensitive are they to the different parameterizations? 
3. How sensitive is the modeled deposition to the imposed emission rates and characteristics, including the gas partitioning of ${ }^{131} \mathrm{I}$ and the size distribution of ${ }^{137} \mathrm{Cs}$ ?

4. How close can model results get to observed deposition given the uncertainties in model physics and inputs, and which of these uncertainties is the most critical?

This paper is organized in the following way: Sect. 2 describes the improvement to the WRF-Chem model and the configuration of the simulations. In Sect. 3, the results are presented and discussed. Section 4 presents a summary and conclusions.

\section{Methodology and data sets}

\subsection{Emissions}

Two emission data sets are used in the simulations: (1) the estimate from the Japan Atomic Energy Agency (JAEA) and (2) the estimate from the Tokyo Electric Power Company (TEPCO). JAEA (Katata et al., 2012; Terada et al., 2012) estimated the release period, duration and emission rate of ${ }^{131} \mathrm{I}$ and ${ }^{137} \mathrm{Cs}$ from a combination of observational data and atmospheric simulations using the System for Prediction of Environmental Emergency Dose Information (SPEEDI). TEPCO (2012) estimated the amount of ${ }^{131}$ I and ${ }^{137} \mathrm{Cs}$ released to the atmosphere using their company's atmospheric dispersion calculation program Dose Information Analysis for Nuclear Accident (DIANA) and the air dose rate measured from a monitoring car that moved around the FDNPP. The emission rates of ${ }^{131} \mathrm{I}$ and ${ }^{137} \mathrm{Cs}$ from 00:00 UTC on 11 March to 23:00 UTC on 31 March from the two data sets are shown in Fig. 1. The emission rate for TEPCO used in this paper is calculated based on the release amount and duration provided by TEPCO. Since the time interval of the emission input for the WRF-Chem model is $1 \mathrm{~h}$, the emission rate over $1 \mathrm{~h}$ intervals is then computed for TEPCO from the data plotted in Fig. 1. If a period for a specific emission rate is less than $1 \mathrm{~h}$, it is treated as $1 \mathrm{~h}$ and the emission rate is computed as the emission amount (during this period) divided by $1 \mathrm{~h}$.

As can be seen from Fig. 1, the emission rate estimated by JAEA is continuous over the simulation period while the emission rate estimated by TEPCO is discontinuous. The most significant release estimated by JAEA covers the period from 12 to 15 March with the peak value on 15 March, while from TEPCO's estimation the peak occurs on 16 March. In our simulations, the source is assumed to be a point source at $37.5^{\circ} \mathrm{N}, 141.0^{\circ} \mathrm{E}$. Moreover, all ${ }^{137} \mathrm{Cs}$ is assumed to be in particulate phase with different size distributions, while the gaseous fraction of ${ }^{131} \mathrm{I}$ varies in different simulations. Note that particle size distributions and the gas partitioning may change during the transport and deposition processes; however, this is not considered in our simulations due to a lack of measurements or studies to allow us to represent this change.

\subsection{Simulation model}

In WRF-Chem, advection, turbulent diffusion, emission, radioactive decay and wet deposition are described using the following Eulerian advection-diffusion-reaction equation:

$$
\frac{\partial A}{\partial t}+\nabla \cdot(\boldsymbol{u} A)=\nabla \cdot\left(\rho \mathbf{K} \nabla\left(\frac{A}{\rho}\right)\right)-\Lambda^{\mathrm{s}} A-\lambda A+E
$$

where $A$ is the air concentration $\left(\mathrm{Bq} \mathrm{m}^{-3}\right)$, which represents the radioactivity per unit volume equivalent to the number of radionuclides that decay per second in a unit volume. $\Lambda^{\mathrm{s}}$ is the wet scavenging rate $\left(\mathrm{s}^{-1}\right) ; \lambda$ represents the (first-order) radioactive decay rate $\left(\mathrm{s}^{-1}\right)$ and $E$ is the point source for the radionuclides. $\mathbf{K}$ is the turbulent diffusivity tensor, which includes the effect of dry deposition. Note that WRF treats the flow as fully compressible. The total number of the radionuclides per $\mathrm{m}^{3}$ at $t=0$ can be calculated from the following equation

$N_{0}=\frac{A_{0}}{\lambda}$

In WRF-Chem, the unit used for transport of gases is ppmv and the unit for transport of aerosols is $\mu \mathrm{g} \mathrm{kg}^{-1}$. However, the unit used in the emission module is $\mathrm{Bq} \mathrm{m}^{-3}$, which is consistent with the unit used in the emission files from JAEA and TEPCO. Therefore, in order to use the default units to calculate the atmospheric transport of the radionuclides, a unit conversion is necessary for input of emissions to WRF, and then to convert its output into $\mathrm{Bq} \mathrm{m}^{-3}$. Based on the Eq. (2):

$$
\begin{aligned}
& \frac{W_{\mathrm{I}}}{V_{\mathrm{m}}}=\frac{A_{\mathrm{I}}}{\lambda_{\mathrm{I}} \mathrm{NA}} 10^{6} \\
& \frac{W_{\mathrm{Cs}}}{M_{\mathrm{Cs}}}=\frac{A_{\mathrm{Cs}}}{\lambda_{\mathrm{Cs}} \mathrm{NA} \rho_{\text {air }}} 10^{6}
\end{aligned}
$$

where $W_{\mathrm{I}}$ is the air concentration of ${ }^{131} \mathrm{I}$ in ppmv; $W_{\mathrm{Cs}}$ is the air concentration of ${ }^{137} \mathrm{Cs}$ in $\mu \mathrm{g} \mathrm{kg}^{-1} ; A_{\mathrm{I}}\left(\mathrm{Bq} \mathrm{m}^{-3}\right)$ is the air concentration of ${ }^{131} \mathrm{I}_{\text {in }} \mathrm{Bq} \mathrm{m}^{-3} ; A_{\mathrm{Cs}}$ is the air concentration of ${ }^{137} \mathrm{Cs}$ in $\mathrm{Bq} \mathrm{m}^{-3} ; M_{\mathrm{I}}\left(\mathrm{g} \mathrm{mol}^{-1}\right)$ is the molar mass of ${ }^{131} \mathrm{I}$; $M_{\mathrm{Cs}}\left(\mathrm{g} \mathrm{mol}^{-1}\right)$ is the molar mass of ${ }^{137} \mathrm{Cs} ; \lambda_{\mathrm{I}}\left(\mathrm{s}^{-1}\right)$ is the radioactive decay rate of ${ }^{131} \mathrm{I} ; \lambda_{\mathrm{Cs}}\left(\mathrm{s}^{-1}\right)$ is the radioactive decay rate of ${ }^{137} \mathrm{Cs}$; NA $\left(\mathrm{mol}^{-1}\right)$ is the Avogadro constant; $V_{\mathrm{m}}$ $\left(\mathrm{m}^{3} \mathrm{~mol}^{-1}\right)$ is the molar volume of the air; and $\rho_{\text {air }}\left(\mathrm{kg} \mathrm{m}^{-3}\right)$ is the air density.

Applying the ideal gas law to atmospheric air:

$p V_{\mathrm{m}}=R T$

thus,

$V_{\mathrm{m}}=\frac{R T}{p}=M_{\mathrm{air}} \alpha_{\mathrm{air}}$,

where $M_{\text {air }}\left(\mathrm{kg} \mathrm{mol}^{-1}\right)$ is the molar mass of the air and $\alpha_{\text {air }}$ $\left(\mathrm{m}^{3} \mathrm{~kg}^{-1}\right)$ is the specific volume of the air. 

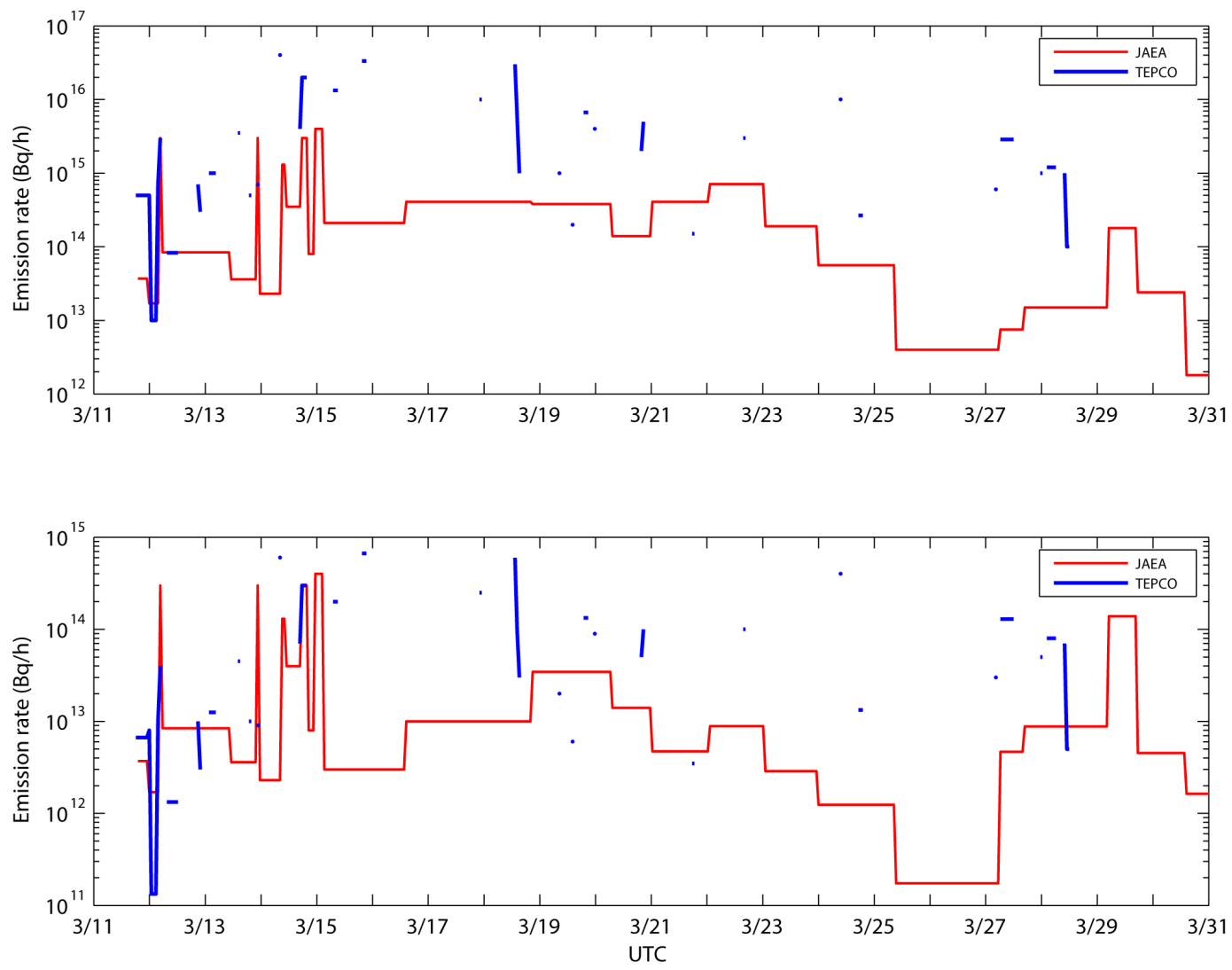

Figure 1. The estimated emission rates of ${ }^{131} \mathrm{I}$ and ${ }^{137} \mathrm{Cs}$. Top panel: ${ }^{131} \mathrm{I}$. Bottom panel: ${ }^{137} \mathrm{Cs}$. The $y$ axis is the hourly radiological activity $\left(\mathrm{Bqh}^{-1}\right)$. The emission rate for TEPCO is calculated based on the release amount and duration provided by TEPCO.

Based on the Eqs. (3) and (4), we obtain the following equations,

$$
\begin{aligned}
& W_{\mathrm{I}}=\frac{A_{\mathrm{I}} M_{\mathrm{air}} \alpha_{\mathrm{air}}}{\lambda_{\mathrm{I}} \mathrm{NA}} 10^{6} \\
& W_{\mathrm{Cs}}=\frac{A_{\mathrm{Cs}} M_{\mathrm{Cs}} \alpha_{\mathrm{air}}}{\lambda_{\mathrm{Cs}} \mathrm{NA}} 10^{6} .
\end{aligned}
$$

In the advection-diffusion solver of WRF-Chem, we use $W_{\mathrm{I}}$ and $W_{\mathrm{Cs}}$ to calculate the transport of ${ }^{131} \mathrm{I}$ and ${ }^{137} \mathrm{Cs}$, respectively, and subsequently use $A_{\mathrm{I}}$ and $A_{\mathrm{Cs}}$ converted based on inversion of Eqs. (7) and (8) for the outputs.

\subsection{Parameterizations of removal processes}

To simulate the transport and deposition of radionuclides more realistically, we added the radioactive decay process into the advection-diffusion solver. To examine the performance of different parameterizations in capturing the ground deposition of radionuclides, we improved the default resistance method for dry deposition and added two new dry deposition parameterization schemes: (1) the simple method and (2) the constant deposition velocity method. Furthermore, we implement a parameterization based on the relative humidity for wet deposition, in addition to the default WRFChem parameterization based on the precipitation rate.

\subsubsection{Radioactive decay}

The radioactive decay is similar to a first-order chemical reaction. The transient air concentration of a radioactive material, $A$, can be described as follows:

$A=A_{0} e^{-\lambda t}$,

where $A_{0}$ represents the air concentration at $t=0$. The radioactive decay rates are taken from IAEA (2001) (International Atomic Energy Agency): $\lambda_{\mathrm{I}}=9.98 \times 10^{-7}\left(\mathrm{~s}^{-1}\right)$ and $\lambda_{\mathrm{Cs}}=7.33 \times 10^{-10}\left(\mathrm{~s}^{-1}\right)$. Considering the low radioactive decay rate of ${ }^{137} \mathrm{Cs}$ (equivalent to a half-life of about 30 years), its decay process is neglected in this study, while the radioactive decay of ${ }^{131} \mathrm{I}$ is retained (half-life of about 8 days).

\subsubsection{Dry deposition}

As presented in Seinfeld and Pandis (2006), we assume that the dry deposition flux is proportional to the local air concentration of the radionuclides at the lowest level of the 
atmospheric model:

$F=-v_{\text {dep }} A$,

where $v_{\text {dep }}$ is the dry deposition velocity. In this study, three different parameterizations of the dry deposition velocity are tested.

\section{The resistance method}

Based on Wesely (1989), the dry deposition velocity for gases is described by three characteristic resistances, as follows:

$v_{\text {dep }}=\frac{1}{r_{\mathrm{a}}+r_{\mathrm{b}}+r_{\mathrm{s}}}$,

where $r_{\mathrm{a}}$ is the aerodynamic resistance; $r_{\mathrm{b}}$ is the quasilaminar layer (viscous sublayer) resistance; and $r_{\mathrm{s}}$ is the surface resistance (describing the resistance of the surface to the uptake/absorption/adsorption of the gas). The parameterizations of these three resistances in our study follows Brandt et al. (2002).

For particles, the surface resistance is neglected while the gravitational settling velocity is considered instead. The deposition velocity for particles can be expressed as Seinfeld and Pandis (2006):

$v_{\text {dep }}=u_{\text {grav }}+\frac{1}{r_{\mathrm{a}}+r_{\mathrm{b}}+r_{\mathrm{a}} r_{\mathrm{b}} u_{\text {grav }}}$,

where $u_{\text {grav }}$ is the gravitational settling velocity. According to Brandt et al. (2002), the gravitational settling velocity can be calculated from the Stokes equation (small particles in the atmosphere experience a creeping flow, Reynolds number $\ll 1$, that appears to change in time due to the larger scale turbulent eddies):

$u_{\text {grav }}=\frac{d_{\mathrm{p}}^{2} g\left(\rho_{\mathrm{p}}-\rho\right) C c}{18 v}$,

where $d_{\mathrm{p}}$ is the particle diameter, $g$ the acceleration of gravity, $\rho_{\mathrm{p}}$ the particle density $\left(1.88 \mathrm{~g} \mathrm{~cm}^{-3}\right.$ for Cesium (Weast, 1988 ) and $3.5 \mathrm{~g} \mathrm{~cm}^{-3}$ (one could also use another typical value $4.93 \mathrm{~g} \mathrm{~cm}^{-3}$ proposed by Baklanov and Sorensen, 2001) for Iodine (Ristovski et al., 2006) (the units of the particle density are converted to $\mathrm{kg} \mathrm{m}^{-3}$ for use in WRFChem)), $\rho$ the density of air, $v$ the kinematic viscosity of air $\left(1.5 \times 10^{-5} \mathrm{~m}^{2} \mathrm{~s}^{-1}\right)$ and $\mathrm{Cc}$ is the Cunningham correction factor given by (Brandt et al., 2002).

$\mathrm{Cc}=1+\frac{\lambda_{\text {air }}}{d_{\mathrm{p}}}\left(2.514+0.80 \exp \left(-\frac{0.55 d_{\mathrm{p}}}{\lambda_{\text {air }}}\right)\right)$,

where $\lambda_{\text {air }}=6.53 \times 10^{-8} \mathrm{~m}$ is the mean free path at standard temperature and pressure.

For particles, it can be seen in Eq. (12) that the dry deposition velocity not only depends on the gravitational settling velocity $u_{\text {grav }}$, but also depends on the aerodynamic resistance $r_{\mathrm{a}}$ and the quasi-laminar layer resistance $r_{\mathrm{b}}$, all of which are affected by the particle density $\rho_{\mathrm{p}}$. However, when taken together, the particle density does not affect the simulation results of the dry deposition considerably.

\section{The simple parameterization}

According to Brandt et al. (2002), the dry deposition velocity can be calculated by a simple parameterization based on the friction velocity and the Obukhov length:

$v_{\text {dep }}=\frac{u_{*}}{a}, L>0:$ stable conditions,

$v_{\text {dep }}=\frac{u_{*}}{a}\left(1+\left(\frac{300}{-L}\right)^{2 / 3}\right), L<0:$ unstable conditions,

where $u_{*}$ is the friction velocity and $L$ is the Obukhov length (Stull, 1988); $a$ is a constant, which for low vegetation is set to 500 and for forests to 100 (Brandt et al., 2002).

\section{The constant deposition velocity method}

In this parameterization, the dry deposition velocity is simply a constant. We use typical values for ${ }^{131} \mathrm{I}$ and ${ }^{137} \mathrm{Cs}$ that are found in the literature: the dry deposition velocity of gasphase ${ }^{131} \mathrm{I}$ is $0.5\left(\mathrm{~cm} \mathrm{~s}^{-1}\right)$ (Baklanov and Sorensen, 2001), the dry deposition velocity of particulate ${ }^{131} \mathrm{I}$ is $0.1\left(\mathrm{~cm} \mathrm{~s}^{-1}\right)$ (Baklanov and Sorensen, 2001) and the dry deposition velocity of ${ }^{137} \mathrm{Cs}$ is $0.05\left(\mathrm{~cm} \mathrm{~s}^{-1}\right)$ (Maryon et al., 1991) (the units of all deposition velocities are converted to $\mathrm{m} \mathrm{s}^{-1}$ for use in WRF-Chem). One could also use other typical values as the dry deposition velocity for both ${ }^{131} \mathrm{I}$ and ${ }^{137} \mathrm{Cs}$ (e.g., as reported by Sportisse (2007), the dry deposition velocity of gas-phase ${ }^{131}$ I could range from 0.1 to $0.5 \mathrm{~cm} \mathrm{~s}^{-1}$, while the dry deposition velocity of ${ }^{137} \mathrm{Cs}$ could range from 0.04 to $0.31 \mathrm{~cm} \mathrm{~s}^{-1}$ ).

In this study, the accumulated dry deposition at each location is calculated. The decay process of radionuclides after they reach the ground surface follows the same radioactive decay rate. In addition, additional decay can occur due to soil activity; this additional decay can be represented by a constant $\lambda_{\mathrm{s}}$, which has the same units as the radioactive decay $\left(\mathrm{s}^{-1}\right)$. Thus, the accumulated ground deposition can be computed using the following equation:

$D_{\mathrm{gr}}(t)=\int_{t_{0}}^{t}-v_{\mathrm{dep}} A \mathrm{e}^{-\left(\lambda+\lambda_{\mathrm{s}}\right) t} \mathrm{~d} t$,

where $D_{\mathrm{gr}}\left(\mathrm{Bq} \mathrm{m}^{-2}\right)$ is the accumulated ground deposition, $t_{0}$ the initial time of deposition, $t$ the duration after deposition, and $\lambda$ the (first-order) radioactive decay rate $\left(\mathrm{s}^{-1}\right)$. In this study, the reduction rate due to soil activity $\lambda_{\mathrm{S}}$ of ${ }^{131} \mathrm{I}$ and ${ }^{137} \mathrm{Cs}$ are specified as 0 and $1.62 \times 10^{-9}\left(\mathrm{~s}^{-1}\right)$, respectively (IAEA, 2001). 


\subsubsection{Wet deposition}

\section{The parameterization based on precipitation rate}

Following Sportisse (2007), the wet deposition rate is described as follows:

$\Lambda^{\mathrm{s}}=a p_{0}^{b}$

where $p_{0}$ is the rain intensity $\left(\mathrm{mm} \mathrm{h}^{-1}\right) ; a$ and $b$ are the parameters for specified radionuclides, which are not dimensionless. In this study, we set $a=4 \times 10^{-5}$ and $b=0.6$ for gaseous ${ }^{131} \mathrm{I}$ (Sportisse, 2007, $a=7 \times 10^{-5}$ and $b=0.69$ for particulate ${ }^{131} \mathrm{I}$ (Jylha, 1991), and $a=8 \times 10^{-5}$ and $b=0.8$ for ${ }^{137} \mathrm{Cs}$ (Baklanov and Sorensen, 2001).

\section{The parameterization based on relative humidity}

The parameterization based on the relative humidity $(\mathrm{RH})$ is another scheme for calculating the wet deposition rate (Pudykiewicz, 1989):

$$
\begin{aligned}
& \Lambda^{\mathrm{s}}=0, \quad \mathrm{RH}<\mathrm{RH}_{\mathrm{t}}, \\
& \Lambda^{\mathrm{s}}=3.5 \times 10^{-5}\left(\frac{\mathrm{RH}-\mathrm{RH}_{t}}{\mathrm{RH}_{\mathrm{s}}-\mathrm{RH}_{t}}\right), \quad \mathrm{RH} \geq \mathrm{RH}_{t},
\end{aligned}
$$

where $\mathrm{RH}_{t}(=80 \%)$ is the threshold value of the relative humidity and $\mathrm{RH}_{\mathrm{S}}(=100 \%)$ is the saturation value.

Similar to the accumulated dry deposition, in this study, the accumulated wet deposition is also calculated. The same constants for the increased decay rates due to soil activity of ${ }^{131} \mathrm{I}$ and ${ }^{137} \mathrm{Cs}$ are used for wet and dry deposition. In addition, the wet deposition rate $\Lambda^{\mathrm{s}}$ is height-dependent in this RH-based model. Following (Seinfeld and Pandis, 2006), the wet ground deposition can be calculated following:

$$
W_{\mathrm{gr}}(t)=\int_{t_{0}}^{t} \int_{0}^{\mathrm{h}} \Lambda^{\mathrm{s}}(z) A(z) \mathrm{e}^{-\left(\lambda+\lambda_{\mathrm{s}}\right) t} \mathrm{~d} z \mathrm{~d} t
$$

where $W_{\mathrm{gr}}\left(\mathrm{Bq} \mathrm{m}^{-2}\right)$ is the wet ground deposition and $h$ is the height of the domain.

\subsection{WRF configurations}

The simulations are performed using three nested domains with horizontal resolutions of 9,3 , and $1 \mathrm{~km}$ for domain 1 , domain 2, and domain 3, respectively (see Fig. 2). Domain 1 and domain 2 are centered at $37.5^{\circ} \mathrm{N}, 141.0^{\circ} \mathrm{E}$ with 160 grid points in both the north-south direction and the east-west direction. Domain 1 nearly covers the whole of Japan, and domain 2 covers most of the Tohoku region and the Kanto region where observational stations are located. The innermost domain has $160 \times 160$ grids and is centered at $36.9^{\circ} \mathrm{N}$, $140.4^{\circ} \mathrm{E}$.

The simulation uses 27 vertical levels for all domains, with the highest level at the $10000 \mathrm{~Pa}$ isobaric surface (WRF uses terrain following pressure coordinates in the vertical direction). The emissions are only released at the lowest level which is about $25 \mathrm{~m}$. The release height reported in the literature primarily ranges from 20 to $150 \mathrm{~m}$ but sometimes extended up to $1 \mathrm{~km}$ (Korsakissok et al., 2013; Stohl et al., 2012). However, accurate data on the vertical distribution of the emissions is still absent, which remains a source of uncertainty when simulating the transport and deposition from the Fukushima accident. The Global Forecasting System (GFS) reanalysis, with a $0.5^{\circ} \times 0.5^{\circ}$ horizontal resolution, is used for initial and boundary conditions. The simulation period starts from 00:00 UTC, 11 March and ends at 00:00 UTC, 31 March 2011 with $1 \mathrm{~h}$ output interval. In this study, we conduct one reference case simulation (REF) and 12 sensitivity simulations as summarized in Table 1. One-way nesting is used for all simulations. Other physics schemes that are not changed include: (1) the Rapid Radiative Transfer Model for long wave radiation, (2) the Dudhia scheme for short wave radiation, (3) the Yonsei University scheme for the planetary boundary layer, (4) the Noah land-surface model for nonurban land-surface physics, (5) the single-layer urban canopy model for urban-surface physics, (6) the new Grell scheme for cumulus parameterization (in this study, cumulus parameterization is only used for the domain 1; the other domains have fine resolutions that should allow them to resolve shallow convection).

\subsubsection{Reference simulation}

Simple aerosol treatment, using an aerosol scheme in which no direct or indirect effects are considered, is used. In the reference case (case REF, as shown in Table 1), the 2-D Smagorinsky scheme is used for horizontal diffusion and the WSM 6 (WRF Single-Moment 6-Class) scheme is used for the microphysics. The resistance method is used for parameterizing dry deposition and the parameterization based on precipitation rate is used for wet deposition. The partitioning of ${ }^{131} \mathrm{I}$ at the source is chosen to be $80 \%$ gas as recommended by several studies (Korsakissok et al., 2013; Morino et al., 2011). Moreover, in the reference case, the size distribution of particulate radionuclides is not taken into account: all particulate radionuclides have the same size, which is the average value. The average size of ${ }^{131} \mathrm{I}$ and ${ }^{137} \mathrm{Cs}$ are chosen to be 0.48 and $0.67 \mu \mathrm{m}$, respectively (Sportisse, 2007; Kaneyasu et al., 2012). In addition, one could also use particle size values of ${ }^{131} \mathrm{I}$ and ${ }^{137} \mathrm{Cs}$ as $0.7 \mu \mathrm{m}$ and $1.0-1.5 \mu \mathrm{m}$, respectively (Masson et al., 2013) to perform similar simulations.

\subsubsection{Sensitivity studies}

As shown in Table 1, a variety of sensitivity simulations are carried out to evaluate the impact of different physics/parameterizations on the atmospheric transport and ground deposition of radionuclides. In case EM2, the 


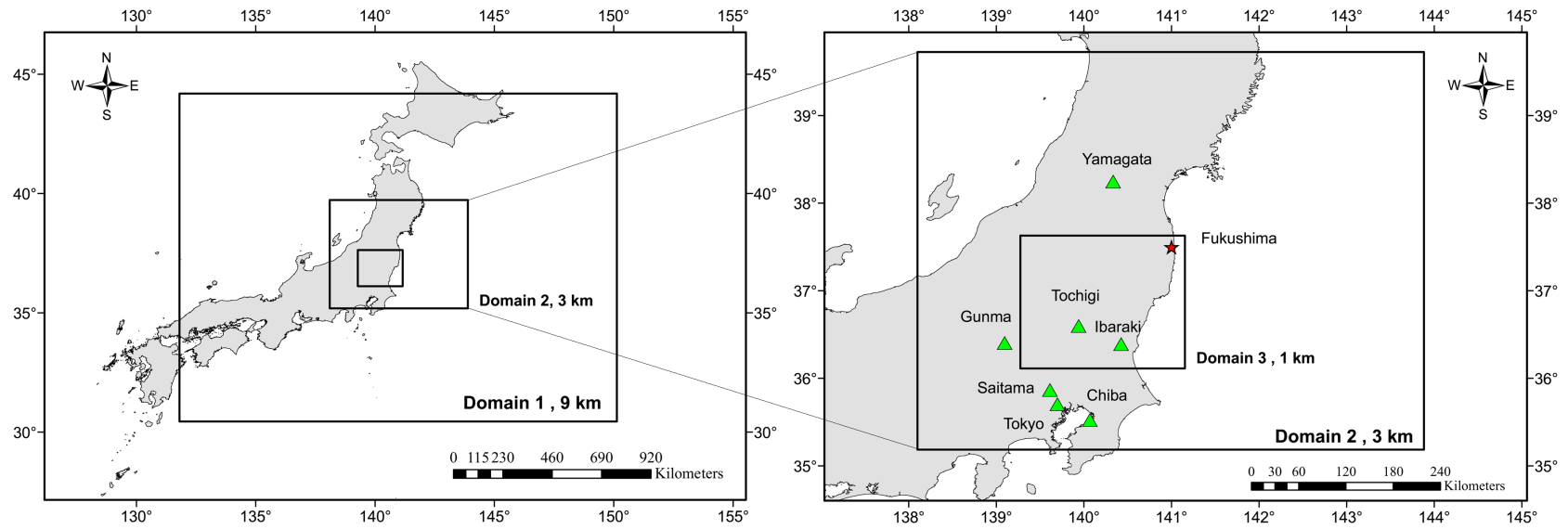

Figure 2. The WRF domain configurations and observational stations. Left: domain 1, 2 and 3. Right: domain 2 and 3 . The red star on the right panel represents FDNPP (source of radioactive release) and the green triangles represent observational stations where deposition of radionuclides was measured (other stations are used for evaluation of the meteorological outputs of WRF).

Table 1. Description of WRF simulations. In the column for wet deposition, "precipitation" is short for the parameterization based on precipitation and "RH" is short for the parameterization based on relative humidity.

\begin{tabular}{llllllll}
\hline Simulations & Emissions & Microphysics & $\begin{array}{l}\text { Horizontal } \\
\text { diffusion scheme }\end{array}$ & $\begin{array}{l}\text { Gaseous fraction } \\
\text { of }{ }^{131} \mathrm{I}\end{array}$ & $\begin{array}{l}\text { Size } \\
\text { distribution }\end{array}$ & $\begin{array}{l}\text { Dry } \\
\text { deposition }\end{array}$ & $\begin{array}{l}\text { Wet } \\
\text { deposition }\end{array}$ \\
\hline REF & JAEA & WSM 6 & Smagorinsky & $80 \%$ & Constant size & Resistance & Precipitation \\
EM2 & TEPCO & WSM 6 & Smagorinsky & $80 \%$ & Constant size & Resistance & Precipitation \\
MP2 & JAEA & Goddard & Smagorinsky & $80 \%$ & Constant size & Resistance & Precipitation \\
MP3 & JAEA & Thompson & Smagorinsky & $80 \%$ & Constant size & Resistance & Precipitation \\
DIF2 & JAEA & WSM 6 & 1.5-order TKE & $80 \%$ & Constant size & Resistance & Precipitation \\
GP2 & JAEA & WSM 6 & Smagorinsky & $100 \%$ & Constant size & Resistance & Precipitation \\
GP3 & JAEA & WSM 6 & Smagorinsky & $60 \%$ & Constant size & Resistance & Precipitation \\
GP4 & JAEA & WSM 6 & Smagorinsky & $30 \%$ & Constant size & Resistance & Precipitation \\
GP5 & JAEA & WSM 6 & Smagorinsky & $0 \%$ & Constant size & Resistance & Precipitation \\
SD2 & JAEA & WSM 6 & Smagorinsky & $80 \%$ & Log-normal & Resistance & Precipitation \\
DRY2 & JAEA & WSM 6 & Smagorinsky & $80 \%$ & Constant size & Simple & Precipitation \\
DRY3 & JAEA & WSM 6 & Smagorinsky & $80 \%$ & Constant size & Constant $v_{\mathrm{d}}$ Precipitation \\
WET2 & JAEA & WSM 6 & Smagorinsky & $80 \%$ & Constant size & Resistance & RH \\
\hline
\end{tabular}

emission rate estimated by TEPCO is used to assess the uncertainty in the emission source term and its impact. In cases MP2 and MP3, two different microphysics schemes, the Goddard scheme and the Thompson scheme, are used to examine the impact of microphysics schemes on rainfall and on the modeling of transport and deposition of radionuclides. In case DIF2, the horizontal diffusion scheme is chosen to be the 1.5 order TKE scheme, as compared to the Smagorinsky scheme that is used in the reference case. Cases GP2, GP3, GP4 and GP5 are designed to assess the sensitivity of simulated results of ${ }^{131} \mathrm{I}$ to the gas partitioning, with the gaseous fraction of ${ }^{131}$ I decreasing from 100 to $0 \%$. In case SD2, the log-normal size distribution of ${ }^{137} \mathrm{Cs}$ is considered; the average size remains $0.67 \mu \mathrm{m}$ but the standard deviation is set to $1.3 \mu \mathrm{m}$ (Kaneyasu et al., 2012). As compared to the reference case, cases DRY2 and DRY3 use the simple parameterization method and the constant deposition velocity method, respec- tively, to parameterize dry deposition; case WET2 uses the parameterization based on relative humidity for wet deposition.

Errors including percentage bias (PBIAS), percentage root mean square error (PRMSE) and mean bias error (MBE) are used to evaluate the model performance and compare the results from different sensitivity cases. PBIAS and PRMSE are used for wind speed, precipitation and total deposition; while $\mathrm{MBE}$ is only used for evaluating the wind direction for which percentage errors are not adequate (e.g., when the observed value is $1^{\circ}$ and the modeled value is $359^{\circ}$, the PBIAS is $-35800 \%$; when the observed value is $357^{\circ}$ and the modeled value is $359^{\circ}$, the PBIAS is $-0.57 \%$; however the absolute errors of the wind direction under these two conditions are both $2^{\circ}$ ). 

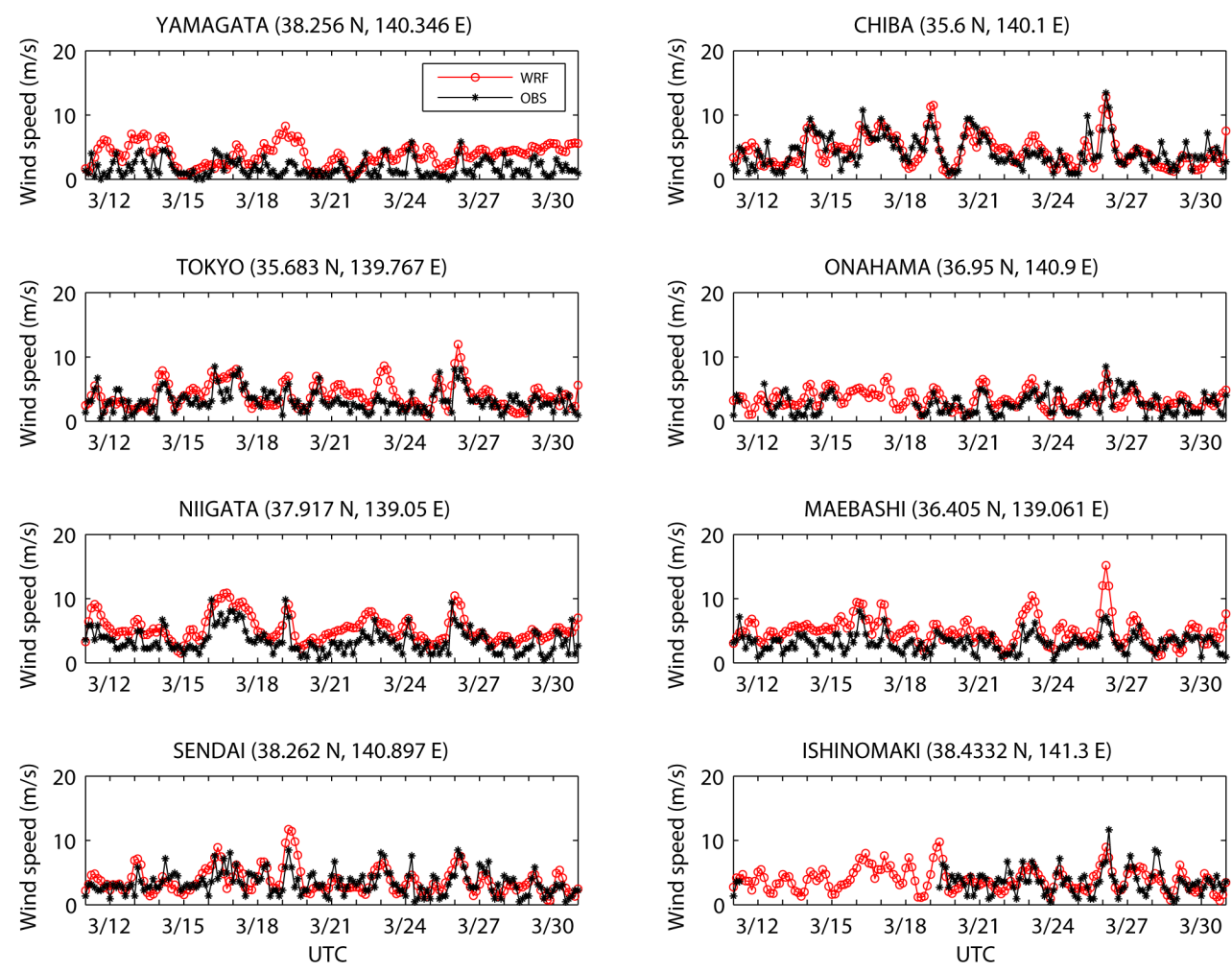

Figure 3. Simulated and observed surface wind speeds at eight stations over Japan during the period from 00:00 UTC, 11 March to 00:00 UTC, 31 March 2011 (case REF). Output from the simulation is collected every 1 hour, but we only display on the figure data with $3 \mathrm{~h}$ resolution for clarity. Red circles represent the simulated data from WRF and the black asterisks represent the observed data.

PBIAS, PRMSE and MBE are defined as follows:

PBIAS $=\frac{\frac{1}{n} \sum_{i=1}^{n}\left(O_{i}-M_{i}\right)}{\frac{1}{n} \sum_{i=1}^{n} O_{i}} \times 100$

PRMSE $=\frac{\sqrt{\frac{1}{n} \sum_{i=1}^{n}\left(O_{i}-M_{i}\right)^{2}}}{\frac{1}{n} \sum_{i=1}^{n} O_{i}} \times 100$

$\mathrm{MBE}=\frac{1}{n} \sum_{i=1}^{n}\left(O_{i}-M_{i}\right)$

where $O_{i}$ represents the observed value and $M_{i}$ represents the modeled value.

\subsection{Observational data sets}

Hourly wind speed, wind direction ${ }^{1}$ and rainfall ${ }^{2}$ data are obtained from National Climatic Data Center (NCDC) at stations YAMAGATA, CHIBA, TOKYO, ONAHAMA, NIIGATA, MAEBASHI, SENDAI and ISHINOMAKI. These data are used to assess the WRF-simulated wind and rainfall fields. Daily total deposition of ${ }^{131} \mathrm{I}$ and ${ }^{137} \mathrm{Cs}$ are measured by bulk samplers over 46 stations, which are provided

\footnotetext{
${ }^{1}$ http://cdo.ncdc.noaa.gov/pls/plclimprod/poemain.cdobystn? dataset $=\mathrm{DS} 3505 \&$ StnList $=47409099999$

${ }^{2} \mathrm{http} / / / \mathrm{www} . n c d c . n o a a . g o v / c d o-w e b /$ datasets/GHCND/ stations/GHCND:JA000047409/detail
}

by Ministry of Education, Culture, Sports, Science and Technology (MEXT) ${ }^{3}$. In this study, we only select 7 of the 46 stations to evaluate the model since most of the stations do not have available data covering the period from 18 to 31 March (all of the 46 stations do not have available data before $18 \mathrm{March}$ ). The seven stations are YAMAGATA, IBARAKI, TOCHIGI, GUNMA, SAITAMA, CHIBA and TOKYO.

\section{Results and discussion}

This section is organized in the following way: in Sect. 3.1, the simulated wind and rainfall fields are evaluated, and their impact on the atmospheric transport and ground deposition of radionuclides is assessed. Sect. 3.2 analyzes the contributions of dry and wet deposition to total deposition and examines the sensitivity of ground deposition to different parameterizations of dry and wet deposition. Section 3.3 examines the sensitivity of ground deposition to the different characteristics of the emission rate, the gas partitioning of ${ }^{131} \mathrm{I}$ and the size distribution of ${ }^{137} \mathrm{Cs}$.

\footnotetext{
${ }^{3}$ http://www.mext.go.jp/english/incident/1303959.htm
} 

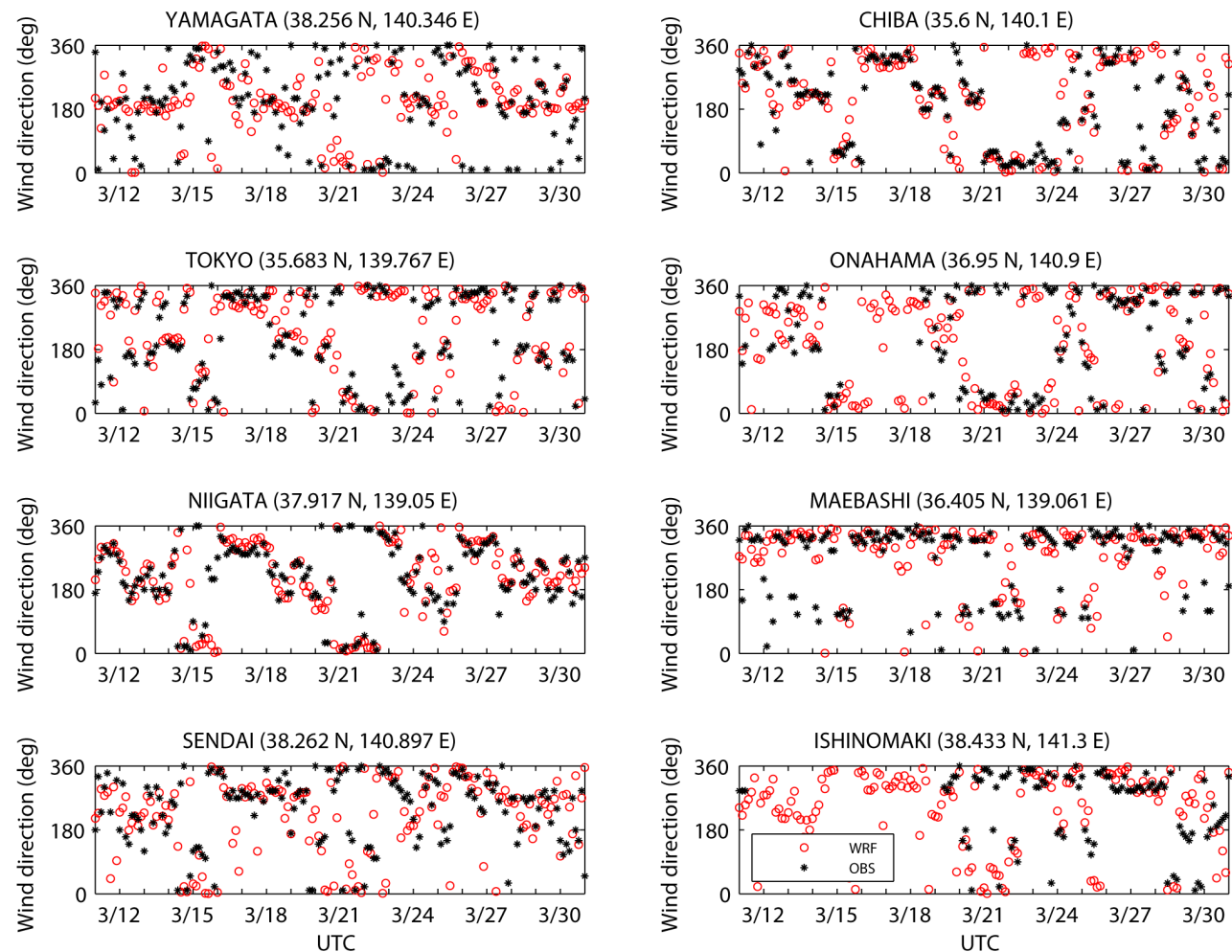

Figure 4. Simulated and observed surface wind directions at eight stations over Japan during the period from 00:00 UTC, 11 March to 00:00 UTC, 31 March 2011 (case REF). Output from the simulation is collected every 1 hour, but we only display on the figure data with $3 \mathrm{~h}$ resolution for clarity. Red circles represent the simulated data from WRF and the black asterisks represent the observed data.

\subsection{Meteorological fields and their influence on deposition of radionuclides}

This section evaluates the WRF-simulated wind and rainfall fields using observational data at various locations. The impact of wind and rainfall on the atmospheric transport and ground deposition of radionuclides is also examined. In particular, the sensitivity of deposition to different microphysical parameterizations and horizontal diffusion schemes in WRF is investigated.

\subsubsection{Evaluation of WRF-simulated wind and rainfall fields and their sensitivity to the horizontal diffusion and microphysics schemes}

WRF-simulated wind speed and direction at $10 \mathrm{~m}$ in the reference case (REF) from domain 2 are compared to observed data over eight stations in Japan and the results are shown in Figs. 3 and 4. The wind fields simulated by WRF show a good agreement with the observations at most of the stations such as CHIBA, SENDAI and ISHINOMAKI. Nevertheless, WRF significantly overestimated the wind speed at YAMAGATA during the whole simulation period, with correspondingly large biases in wind direction at that station.

The biases in the WRF-simulated wind fields are quantified using PBIAS, PRMSE, and MBE as introduced in Sect. 2
(Table 2). These statistics are also calculated for the case using the 1.5-order TKE horizontal diffusion scheme (DIF2) in addition to the reference case (REF). In the Smagorinsky scheme, the horizontal diffusion coefficient $K$ is diagnosed from the horizontal strain rate magnitude, while in the 1.5 TKE scheme a prognostic equation for turbulent kinetic energy (TKE) is used, and $K$ is based on the TKE. The vertical diffusion coefficient for both cases are computed by the Planetary Boundary Layer (PBL) scheme. The values of PBIAS, PRMSE and MBE are quite close for both cases. However, as shall be seen later, the subtle differences in the wind fields generated by using two different horizontal diffusion schemes can result in significant differences in the ground deposition of radionuclides. It is clear that the PBIAS for wind speed at CHIBA, SENDAI and ISHINOMAKI are lower than $7 \%$ and the PRMSE at these three stations are also lower than at other stations. The PBIAS and PRMSE for wind speed at YAMAGATA are significantly higher than those at other stations, which is in agreement with Figs. 3 and 4. As for the wind direction, the MBE at CHIBA, NIIGATA and ISHINOMAKI are lower than $30^{\circ}$. Nevertheless, at YAMAGATA, the MBE of wind direction is about $50^{\circ}$ for both diffusion schemes. The YAMAGATA station is located in an area surrounded by mountains, thus the large biases in the simulated wind speed and wind direction at YAMAGATA 

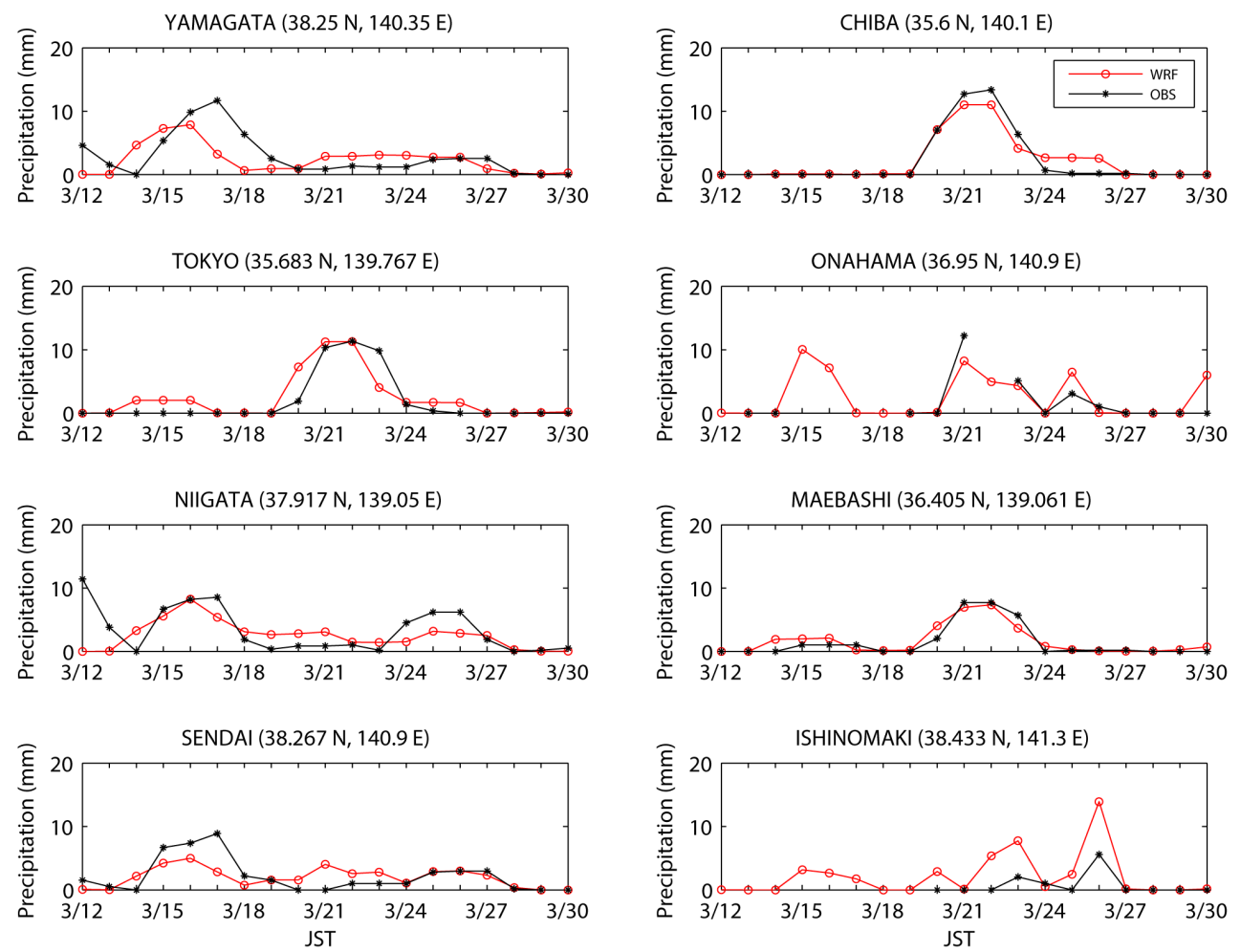

Figure 5. Simulated and observed daily precipitation at eight stations over Japan during the period from Japan standard time (JST $=$ UTC +9) 11 to 31 March 2011. Red circles represent the simulated data from WRF and the black asterisks represent the observed data.

may be due to the coarse grid resolution ( $3 \mathrm{~km}$, domain 2 ) that is unable to resolve the subgrid-scale topography.

The simulated daily precipitation rate in the reference case (REF) is also compared to observational data at the eight stations and the results are shown in Fig. 5. The WRF-simulated daily precipitation is in good agreement with the observations except at YAMAGATA, SENDAI, and ISHINOMAKI. At YAMAGATA, the WRF-simulated rainfall is a day ahead of the observed rainfall and the maximum rainfall rate is significantly underestimated by WRF. At SENDAI and ISHINOMAKI, the maximum rainfall rate is not captured well by WRF, but the timing is almost correct. In order to examine the sensitivity of simulated rainfall to different microphysical parameterizations, the precipitation patterns generated from three different microphysics schemes are compared in Fig. 6 (REF with WSM 6, MP2 with Goddard, MP3 with Thompson). The left panels show the daily precipitation on 21 March and the right panels show the accumulated precipitation from 11 to 31 March over domain 2. Both the daily precipitation on 21 March and the accumulated precipitations show quite similar patterns overall, but there are differences observed among the three cases with the different microphysical parameterizations. For example, in the left panels, around $35.5-36^{\circ} \mathrm{N}, 138.5-140.5^{\circ} \mathrm{E}$ (as outlined by the black circles in Fig. 6) where the maximum precipitation occurs, the area with high precipitation values (> $20 \mathrm{~mm})$ in case REF or MP2 is significantly larger than that in case MP3.

The errors associated with the simulated rainfall fields are quantified by PBIAS and PRMSE, as shown in Table 3. It is clear that the PBIAS values at most of the stations are lower than $30 \%$ while the PRMSE values are about $200 \%$; this indicates that although there are large biases associated with the time series of rainfall, a significant fraction of these biases are related to timing and the averaged or the accumulated rainfall (which cancel the timing errors and are hence more accurately represented by PBIAS) are fairly well captured by WRF. This is not the case at station ISHINOMAKI where the values of PRMSE and PBIAS are extremely high. This is because the observational data at this station is only available after 20 March when the precipitation is significantly overestimated by WRF simulations (as shown in Fig. 5). The comparison among the three microphysical schemes shows that case REF yields the least PBIAS at CHIBA, NIIGATA, MAEBASHI, SENDAI, and ISHINOMAKI. In particular, the PBIAS from case REF are significantly smaller than those from cases MP2 and MP3 at NIIGATA, MAEBASHI, and SENDAI. At TOKYO, the PBIAS from case REF is comparable to that from case MP2, while at ONAHAMA it is comparable to that from case MP3. Only at YAMAGATA does the REF case produce the largest PBIAS; nonetheless, all of the three microphysical schemes 
Table 2. The PBIAS and PRMSE of wind speed and MBE of wind direction with different horizontal diffusion schemes. "YA", "CH", "TOK", "ON", "NI", "MA", "SE” and "IS” represent the stations "YAMAGATA", "CHIBA', "TOKYO”, "ONAHAMA", "NIIGATA", "MAEBASHI", "SENDAI" and "ISHINOMAKI", respectively.

\begin{tabular}{llrrrrrrrr}
\hline Errors & Cases & YA & CH & TOK & ON & NI & MA & SE & IS \\
\hline PBIAS of & REF & $124 \%$ & $4 \%$ & $28 \%$ & $16 \%$ & $58 \%$ & $57 \%$ & $7 \%$ & $4 \%$ \\
wind speed & DIF2 & $127 \%$ & $2 \%$ & $27 \%$ & $19 \%$ & $57 \%$ & $64 \%$ & $11 \%$ & $3 \%$ \\
\hline PRMSE of & REF & $170 \%$ & $51 \%$ & $73 \%$ & $62 \%$ & $76 \%$ & $93 \%$ & $65 \%$ & $56 \%$ \\
wind speed & DIF2 & $176 \%$ & $50 \%$ & $73 \%$ & $63 \%$ & $76 \%$ & $98 \%$ & $64 \%$ & $56.57 \%$ \\
\hline MBE of wind & REF & 49.2 & 28.4 & 32.7 & 34.3 & 24.9 & 37.0 & 43.1 & 30.3 \\
direction & DIF2 & 50.0 & 30.9 & 31.4 & 33.6 & 23.5 & 36.2 & 42.2 & 26.7 \\
\hline
\end{tabular}

yield very small PBIAS at YAMAGATA. As such, it can be concluded that the WSM 6 microphysical scheme used in case REF performs the best among the three schemes examined here, at least for this study.

\subsubsection{Influence of wind and rainfall on the transport and deposition of radionuclides}

In order to illustrate the impact of wind fields on the atmospheric transport of radionuclides, the concentration maps of ${ }^{131} \mathrm{I}$ at the lowest level of the atmospheric model at four different times (i.e., 00:00, 06:00, 12:00, 18:00 UTC) on 21 March are illustrated in the upper four panels of Fig. 7, along with wind vector field. At 00:00 UTC, the transport of the radionuclides from FDNPP is driven by northerly winds (towards the south). One can also notice the large concentrations to the east, over the Pacific Ocean, and to the north of FDNPP at 00:00 UTC that are probably the remnants of pervious northeastward winds. The transport direction changes with wind and becomes northeasterly (towards the southwest, from the source to the Kanto region) from 12:00 to 18:00 UTC gradually. The bottom panels of Fig. 7 shows the accumulated daily dry and wet deposition on 21 March. As suggested by the concentration maps, the deposition is highest in the Kanto region that lies southwest of FDNPP. Dry deposition is small compared with wet deposition and the two depositions display different spatial patterns. In this REF case, the parameterization of wet deposition is based on precipitation. As shown in Fig. 6, there is a large amount of precipitation in the southwest area and hence the wet deposition is also high over this area. Thus, it is evident that the ground deposition, including dry and wet deposition, is influenced by both wind and rainfall.

The total deposition from cases using different horizontal diffusion schemes and microphysical schemes are compared in Fig. 8, where we show the daily total deposition at stations YAMAGATA and CHIBA as two examples. Both of the two stations have typical terrains of Japan, but they are different: The YAMAGATA station is located in the north of Japan (on the northwest of FDNPP), where surrounded by mountains, while the CHIBA station is located in the Kanto Plain (on the south of FDNPP). The results of both ${ }^{131} \mathrm{I}$ and ${ }^{137} \mathrm{Cs}$ indicate that the difference between REF and DIF2 is small at CHIBA but large at YAMAGATA. At YAMAGATA, the total daily deposition of both ${ }^{131} \mathrm{I}$ and ${ }^{137} \mathrm{Cs}$ in REF is only about half of that in DIF2 on 20 March, while it is slightly higher in DIF2 than that in REF on 22 and 25 March. Much larger differences are seen among different microphysics schemes at both CHIBA and YAMAGATA. For example, at YAMAGATA on 20 March, the deposition of ${ }^{137} \mathrm{Cs}$ simulated by REF is about $3.9 \mathrm{kBq} \mathrm{m}^{-2}$ and it is close to the observed value; while in MP2 and MP3, the amounts of deposition are 2.2 and $7.9 \mathrm{kBq} \mathrm{m}^{-2}$, respectively. Figure 8 also illustrates that the ground deposition of radionuclides are sensitive to both horizontal diffusion schemes and microphysical schemes. This however does not contradict our previous finding that at the eight stations with measurements of wind speed and wind directions, the biases generated by the two cases using different horizontal diffusion schemes are relatively similar. The daily accumulated ground deposition at one particular location is in fact affected by winds over the upwind fetch as well as turbulence levels at a given location. Hence, despite the fact biases seen in the wind fields over the eight stations are similar for the two horizontal diffusion schemes, the turbulence and upstream winds in the two cases are not necessarily similar. Furthermore, small differences in wind fields can generate relatively larger differences in precipitation patterns and locations and thus influence wet deposition. As such, subtle differences seen in the wind field in Table 2 might result in significant differences in the ground deposition depending on the sensitivity of ground deposition and precipitation to the wind field. In addition, the terrain may also influence the deposition indirectly. For example, the YAMAGATA station is located in an area surrounded by mountains, so the inhomogeneous terrain might not be well described by the coarse resolution ( $3 \mathrm{~km}$, domain 2$)$ simulations (that is, the WRF model is unable to resolve the subgrid-scale topography), which may be an important reason that large biases are witnessed in the simulated precipitation. Considering the complex terrain, subtle differences in the wind fields in this grid box may have larger influence on 

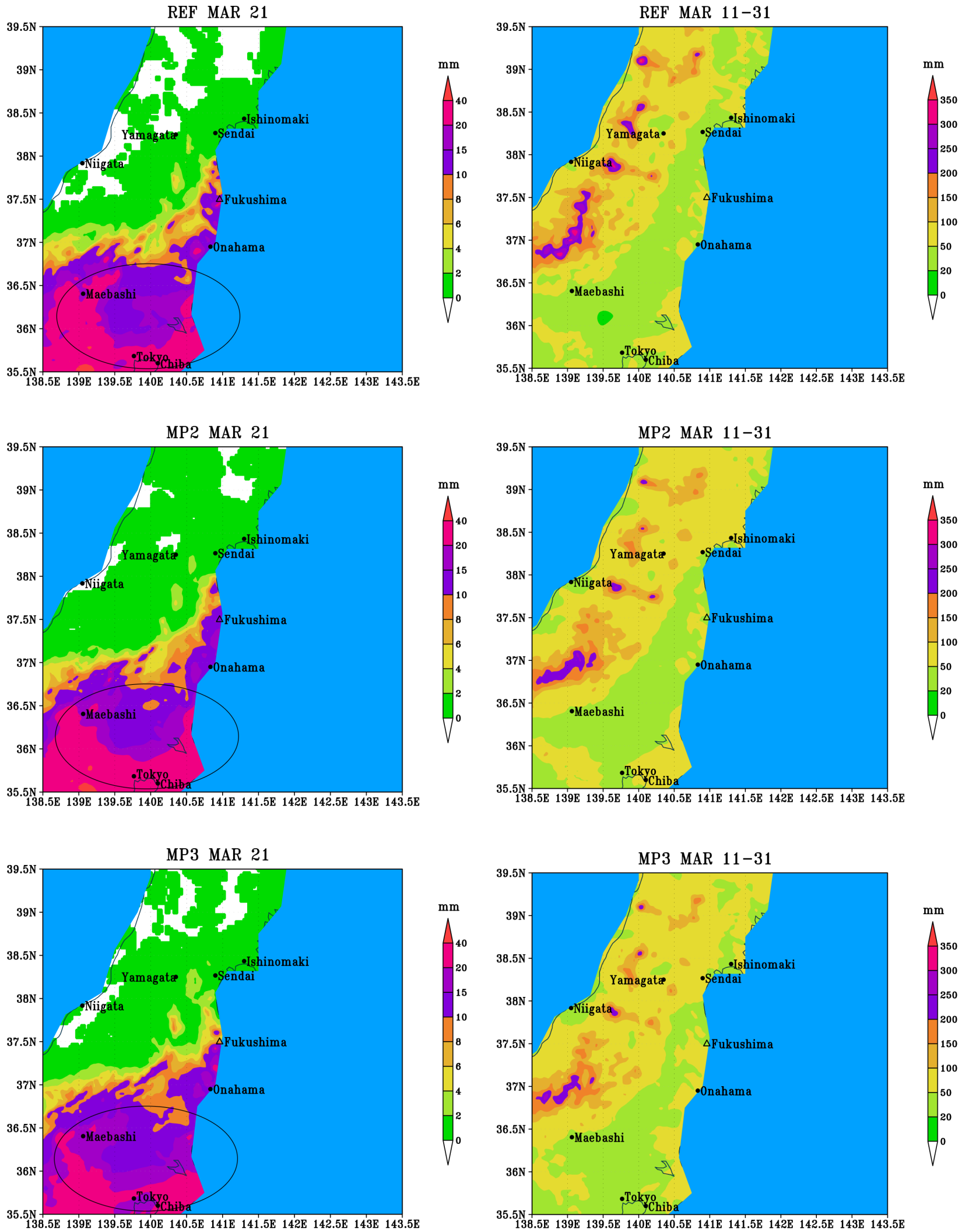

Figure 6. The simulated precipitation over domain 2 with three different microphysics schemes. Microphysics schemes WSM 6, Goddard and Thompson are used in case REF, MP2 and MP3, respectively. The left column shows the daily precipitation on 21 March and the right column shows the accumulated precipitation from 11 to 31 March. 
Table 3. The PBIAS and PRMSE of precipitation with different microphysics schemes. "YA", "CH", "TOK", "ON", "NI", "MA", "SE" and "IS" represent the stations "YAMAGATA", "CHIBA", "TOKYO”, "ONAHAMA", "NIIGATA", "MAEBASHI", "SENDAI" and "ISHINOMAKI", respectively.

\begin{tabular}{llrrrrrrrr}
\hline Errors & Cases & YA & CH & TOK & ON & NI & MA & SE & IS \\
\hline \multirow{2}{*}{ PBIAS } & REF & $-17 \%$ & $2 \%$ & $29 \%$ & $18 \%$ & $-20 \%$ & $14 \%$ & $-7 \%$ & $285 \%$ \\
& MP2 & $5 \%$ & $35 \%$ & $30 \%$ & $13 \%$ & $-33 \%$ & $50 \%$ & $24 \%$ & $489 \%$ \\
& MP3 & $-9 \%$ & $3 \%$ & $1 \%$ & $18 \%$ & $-33 \%$ & $39 \%$ & $28 \%$ & $282 \%$ \\
\hline \multirow{2}{*}{ PRMSE } & REF & $190 \%$ & $101 \%$ & $282 \%$ & $136 \%$ & $182 \%$ & $197 \%$ & $204 \%$ & $463 \%$ \\
& MP2 & $156 \%$ & $153 \%$ & $297 \%$ & $196 \%$ & $177 \%$ & $213 \%$ & $198 \%$ & $1009 \%$ \\
& MP3 & $157 \%$ & $118 \%$ & $250 \%$ & $149 \%$ & $172 \%$ & $156 \%$ & $215 \%$ & $414 \%$ \\
\hline
\end{tabular}

the precipitation than that in the plain, which then generate large differences in precipitation and deposition.

The PBIAS and PRMSE of total deposition of ${ }^{131} \mathrm{I}$ and ${ }^{137} \mathrm{Cs}$ with different horizontal diffusion schemes and microphysics schemes are presented in Tables 4 and 5, respectively. In order to evaluate the performance of different schemes in a quantitative and consistent way, a ranking system is proposed. At each station, a local rank (LR) is assigned to each scheme. The scheme with the smallest error has rank 1 and the scheme with the second smallest error has rank 2, etc. Then a global rank (GR) is calculated by summing the local rank of each scheme over all stations. Finally, the global rank calculated with PBIAS and that calculated with PRMSE are summed up to yield a summed global rank (SR), which is used to compare the performance of different parameterization schemes. A scheme with the smallest SR performs the best among all the schemes that it is compared against. As shown in Table 4, the errors in case REF are close to those in case DIF2. However, the global ranks inferred from PBIAS and PRMSE are lower in case DIF2 than those in case REF for both ${ }^{131} \mathrm{I}$ and ${ }^{137} \mathrm{Cs}$, indicating that, globally, using the 1.5 order TKE scheme predicts the ground deposition better than using the horizontal Smagorinsky scheme.

Table 5 shows the errors in simulated total daily depositions of ${ }^{131} \mathrm{I}$ and ${ }^{137} \mathrm{Cs}$ with different microphysics schemes. It is shown that PBIAS in all three cases are below $100 \%$ over the seven stations except that of ${ }^{137} \mathrm{Cs}$ at TOCHIGI and GUNMA. However, most of the PRMSE values of ${ }^{131} \mathrm{I}$ and ${ }^{137} \mathrm{Cs}$ are larger than $100 \%$, especially in TOCHIGI and GUNMA where the PRMSE of ${ }^{137} \mathrm{Cs}$ is over $1200 \%$ in case MP3 and at least over $400 \%$ in the other two cases, suggesting that the model cannot capture the total daily deposition of ${ }^{137} \mathrm{Cs}$ at these two stations. Case REF has the lowest global rank based on both PBIAS and PRMSE for both ${ }^{131} \mathrm{I}$ and ${ }^{137} \mathrm{Cs}$, which suggests that the microphysics scheme WSM 6 can better predict the total daily deposition than the Goddard scheme and the Thompson scheme. The much higher values of PRMSE compared to PBIAS indicates that a significant component of the errors are due to time shifts in the deposition patterns. Overestimations and underestimations of deposition at various times partially cancel each other in PBIAS, but not in PRMSE. Overall however, since one is interested in total deposition even if the timing if not very accurate, PBIAS might be a better measure of the ability of WRF to simulate the environmental impact of radionuclides deposition from the Fukushima accident.

\subsection{Dry and wet deposition}

This section examines the contributions of dry and wet deposition to total deposition, and examines the sensitivity of ground deposition to different parameterizations of dry and wet deposition processes.

\subsubsection{Contributions of dry and wet deposition to total deposition}

Simulated total daily depositions of ${ }^{131} \mathrm{I}$ and ${ }^{137} \mathrm{Cs}$ from 11 to 31 March at various locations indicate that the total daily depositions of ${ }^{131} \mathrm{I}$ and ${ }^{137} \mathrm{Cs}$ are significant at all of the seven stations during two periods: from 15 to 16 March (not shown) and from 20 to 23 March. These periods with high total daily depositions correspond to periods with high emission rates from the source (Fig. 1). Since there is no observational data for ground deposition before $18 \mathrm{March}$, the following analyses will focus on the period from 18 to 31 March, with maximum total daily depositions occurring from 20 to 23 March.

Comparisons between simulated total daily depositions of ${ }^{131} \mathrm{I}$ and ${ }^{137} \mathrm{Cs}$ and observational data are shown in Fig. 9. During the period from 18 to $31 \mathrm{March}$, simulated total daily depositions generally follow the pattern observed in the measurements; however, the simulations significantly underestimate the observed deposition peak of ${ }^{131}$ I around 20 to 22 March at most stations. As for ${ }^{137} \mathrm{Cs}$, the total daily depositions are overestimated at TOCHIGI, GUNMA and SAITAMA and underestimated at YAMAGATA, IBARAKI and CHIBA, which is consistent with the results reported by Morino et al. (2011) using a CMAQ model coupled with WRF in their study. Morino et al. (2011) indicated that the deposition rates of ${ }^{137} \mathrm{Cs}$ at IBARAKI were underestimated, but those at the TOCHIGI, GUNMA and SAITAMA were overestimated by their model. The reasons of differences between the observed and simulated data are multiple and 

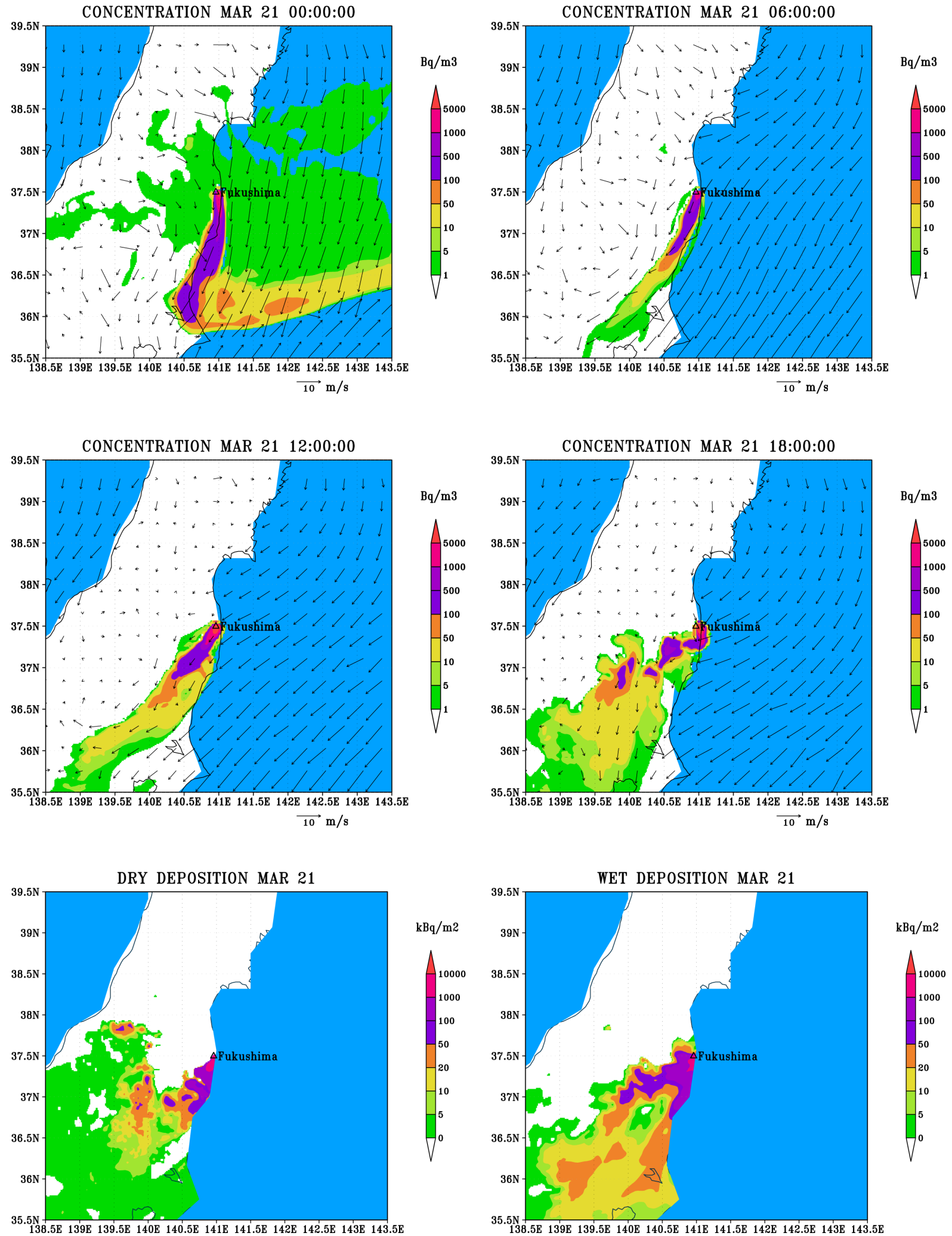

Figure 7. The near-surface concentration and ground deposition of ${ }^{131} \mathrm{I}$ on 21 March. The upper four panels show the distribution of concentration of ${ }^{131} \mathrm{I}$ at the lowest level of the atmospheric model at four different times (i.e., 00:00, 06:00, 12:00, 18:00 UTC) on 21 March, in which the near-surface concentration is represented by instantaneous values. The bottom panels show the dry and wet deposition accumulated during 21 March. The results are from the simulation REF. 

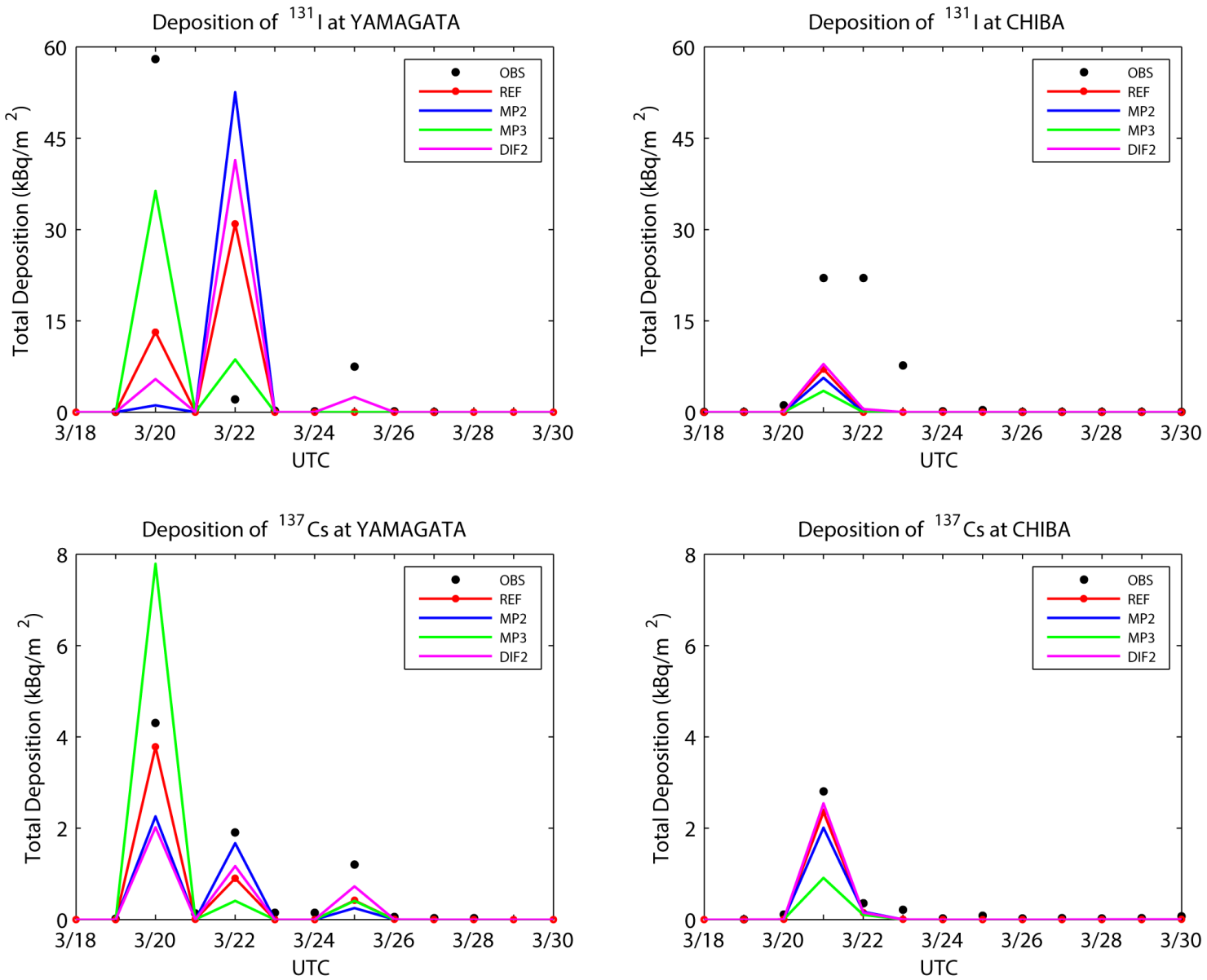

Figure 8. Daily total depositions in station YAMAGATA and CHIBA with different horizontal diffusion and microphysics schemes.

Table 4. The PBIAS and PRMSE of total daily depositions of ${ }^{131} \mathrm{I}$ and ${ }^{137} \mathrm{Cs}$ with different horizontal diffusion schemes. GR represents the global ranks for PBIAS or PRMSE, and SR represents for the sum of the global ranks. The definition of GR and SR is shown in Sect. 3.1.2. "YA', "IB", "TOC", "GU", "SA", "CH" and "TOK" represent the stations "YAMAGATA", "IBARAKI", "TOCHIGI", "GUNMA", "SAITAMA", "CHIBA" and "TOKYO", respectively.

\begin{tabular}{llrrrrrrrrr}
\hline Errors & Cases & YA & IB & TOC & GU & SA & CH & TOK & GR & SR \\
\hline $\begin{array}{l}\text { PBIAS } \\
\text { of }{ }^{131} \mathrm{I}\end{array}$ & REF & $-36 \%$ & $-82 \%$ & $-46 \%$ & $-39 \%$ & $-75 \%$ & $-87 \%$ & $-80 \%$ & 12 & 24 \\
\hline PRMSE & REF & $235 \%$ & $187 \%$ & $149 \%$ & $87 \%$ & $151 \%$ & $187 \%$ & $176 \%$ & 12 & 24 \\
of ${ }^{131} \mathrm{I}$ & DIF2 & $288 \%$ & $183 \%$ & $143 \%$ & $134 \%$ & $150 \%$ & $181 \%$ & $174 \%$ & 9 & 18 \\
\hline PBIAS & REF & $-36 \%$ & $-43 \%$ & $218 \%$ & $157 \%$ & $65 \%$ & $-34 \%$ & $-5 \%$ & 11 & 22 \\
of ${ }^{137} \mathrm{Cs}$ & DIF2 & $-51 \%$ & $-43 \%$ & $203 \%$ & $96 \%$ & $80 \%$ & $-29 \%$ & $-1 \%$ & 9 & 19 \\
\hline PRMSE & REF & $55 \%$ & $167 \%$ & $977 \%$ & $452 \%$ & $369 \%$ & $52 \%$ & $44 \%$ & 11 & 22 \\
of ${ }^{137} \mathrm{Cs}$ & DIF2 & $97 \%$ & $168 \%$ & $972 \%$ & $317 \%$ & $416 \%$ & $39 \%$ & $51 \%$ & 10 & 19 \\
\hline
\end{tabular}

sometimes dependent on each other. The discrepancies are partly due to the uncertainties in emissions and partly due to the uncertainties in the simulated meteorological conditions including wind fields and precipitation. From Fig. 9, it is clear that the total deposition is dominated by wet depo- sition over all of the stations for both ${ }^{131} \mathrm{I}$ and ${ }^{137} \mathrm{Cs}$. The exceptions are TOCHIGI where the dry deposition of ${ }^{131} \mathrm{I}$ contributes about half of the total deposition on 21 March and YAMAGATA where the dry deposition of ${ }^{131} \mathrm{I}$ is about $1 / 3$ of the total deposition on 20 March. 
Table 5. The PBIAS and PRMSE of total daily depositions of ${ }^{131} \mathrm{I}$ and ${ }^{137} \mathrm{Cs}$ with different microphysics schemes. GR represents the global ranks for PBIAS or PRMSE, and SR represents for the sum of the global ranks. The definition of GR and SR is shown in Sect. 3.1.2. "YA", "IB", "TOC", "GU", "SA", "CH" and "TOK" represent the stations "YAMAGATA", "IBARAKI", "TOCHIGI", "GUNMA", "SAITAMA", "CHIBA" and "TOKYO", respectively.

\begin{tabular}{llrrrrrrrrr}
\hline Errors & Cases & YA & IB & TOC & GU & SA & CH & TOK & GR & SR \\
\hline PBIAS & REF & $-36 \%$ & $-82 \%$ & $-46 \%$ & $-39 \%$ & $-75 \%$ & $-87 \%$ & $-80 \%$ & 12 & 23 \\
of ${ }^{131} \mathrm{I}$ & MP2 & $-22 \%$ & $-87 \%$ & $-66 \%$ & $-8 \%$ & $-71 \%$ & $-90 \%$ & $-84 \%$ & 12 & 24 \\
& MP3 & $-34 \%$ & $-89 \%$ & $-51 \%$ & $23 \%$ & $-83 \%$ & $-94 \%$ & $-85 \%$ & 18 & 35 \\
\hline PRMSE & REF & $235 \%$ & $187 \%$ & $149 \%$ & $87 \%$ & $151 \%$ & $187 \%$ & $176 \%$ & 11 & 23 \\
of ${ }^{131} \mathrm{I}$ & MP2 & $334 \%$ & $194 \%$ & $145 \%$ & $79 \%$ & $150 \%$ & $192 \%$ & $181 \%$ & 12 & 24 \\
& MP3 & $104 \%$ & $200 \%$ & $145 \%$ & $173 \%$ & $158 \%$ & $201 \%$ & $182 \%$ & 17 & 35 \\
\hline PBIAS & REF & $-36 \%$ & $-43 \%$ & $218 \%$ & $157 \%$ & $65 \%$ & $-34 \%$ & $-5 \%$ & 10 & 20 \\
of ${ }^{137} \mathrm{Cs}$ & MP2 & $-48 \%$ & $-62 \%$ & $192 \%$ & $297 \%$ & $83 \%$ & $-42 \%$ & $-26 \%$ & 16 & 31 \\
& MP3 & $8 \%$ & $-55 \%$ & $272 \%$ & $496 \%$ & $17 \%$ & $-73 \%$ & $-29 \%$ & 16 & 33 \\
\hline PRMSE & REF & $55 \%$ & $167 \%$ & $977 \%$ & $452 \%$ & $369 \%$ & $52 \%$ & $44 \%$ & 10 & 20 \\
of ${ }^{137}$ Cs & MP2 & $90 \%$ & $169 \%$ & $926 \%$ & $763 \%$ & $431 \%$ & $78 \%$ & $48 \%$ & 15 & 31 \\
& MP3 & $154 \%$ & $142 \%$ & $1216 \%$ & $1207 \%$ & $227 \%$ & $176 \%$ & $50 \%$ & 17 & 33 \\
\hline
\end{tabular}

Figure 10 examines the spatial distribution of accumulated dry and wet depositions of ${ }^{131} \mathrm{I}$ and ${ }^{137} \mathrm{Cs}$ over domain 2 from 11 to 31 March. For ${ }^{131}$ I, the area with dry deposition over $100 \mathrm{kBq} \mathrm{m}^{-2}$ is concentrated near the source and is much smaller than the area with wet deposition over $100 \mathrm{kBq} \mathrm{m}^{-2}$. The spatial distribution of the accumulated wet deposition does not exactly follow that of the accumulated precipitation that was shown in Fig. 6, suggesting that other factors such as wind, concentration fields, and the emission rate also play an important role in determining the distribution of wet deposition. The wet deposition of ${ }^{131} \mathrm{I}$ in the northeast area is much larger than the dry deposition, while along the east coast, the dry deposition is sometimes higher than the wet deposition. This implies that wet deposition does not necessarily dominate over dry deposition at all locations.

As for ${ }^{137} \mathrm{Cs}$, the pattern of dry deposition is quite different from that of ${ }^{131} \mathrm{I}$; and most of the areas have values lower than $5 \mathrm{kBq} \mathrm{m}^{-2}$. The reason for these differences is that the dry deposition parameterizations depend on resistances that are quite different between ${ }^{131} \mathrm{I}$ and ${ }^{137} \mathrm{Cs}$, and the dry deposition velocity of ${ }^{137} \mathrm{Cs}$ is much smaller than that of gaseous ${ }^{131}$ I. The wet deposition, on the other hand, shows a similar pattern to that of ${ }^{131} \mathrm{I}$, but the values are slightly lower than those of ${ }^{131} \mathrm{I}$ in some areas such as north of Fukushima. These comparisons imply that the dry and wet depositions of different radionuclides are affected by wind and rainfall in different ways.

\subsubsection{Sensitivity of ground deposition to the parameterizations of dry and wet deposition}

To assess the sensitivity of total daily depositions to different dry and wet deposition parameterization schemes, the results from cases REF (with the resistance method for dry depo- sition, and with the parameterization based on precipitation rate for wet deposition), DRY2 (with the simple parameterization method for dry deposition), DRY3 (with the constant dry deposition velocity) and WET2 (with the parameterization based on relative humidity) are compared. In Fig. 11 the total daily depositions at stations IBARAKI and TOCHIGI are shown as examples. The deposition from case REF and DRY2 are nearly the same during the whole period. Except for ${ }^{131}$ I at TOCHIGI, the deposition from case DRY3 is also very close to that in case REF and DRY2. The reason why different dry deposition parameterizations do not alter the total daily deposition of ${ }^{131} \mathrm{I}$ at station IBARAKI and those of ${ }^{137} \mathrm{Cs}$ at stations IBARAKI and TOCHIGI significantly is that they are dominated by wet deposition. At TOCHIGI, the dry deposition of ${ }^{131}$ I contributes nearly the same to the total deposition as wet deposition, as can be seen from Fig. 9. As such, the total deposition of ${ }^{131}$ I at TOCHIGI is sensitive to the dry deposition parameterizations in WRF. Nevertheless, the results from REF and DRY2 are still very close for ${ }^{131}$ I at TOCHIGI, suggesting that the resistance method and the simple parameterization yield similar dry daily depositions.

As shown in Fig. 11, the total daily depositions in case WET2 (parameterization based on relative humidity) are significantly lower than those in case REF for both ${ }^{131} \mathrm{I}$ and ${ }^{137} \mathrm{Cs}$ at these two stations. For example, in TOCHIGI, the deposition of ${ }^{137} \mathrm{Cs}$ from case WET2 is only half of that from case REF. Thus, the total deposition is more sensitive to the choice of the wet deposition scheme than to the choice of the dry deposition scheme, which is due to the fact that the total depositions at these two stations are dominated by wet depositions. However, at TOCHIGI, the comparison of the different simulations of ${ }^{131} \mathrm{I}$ (Fig. 11, upper right panel) indicates that the parameterizations of two depositions (i.e., 

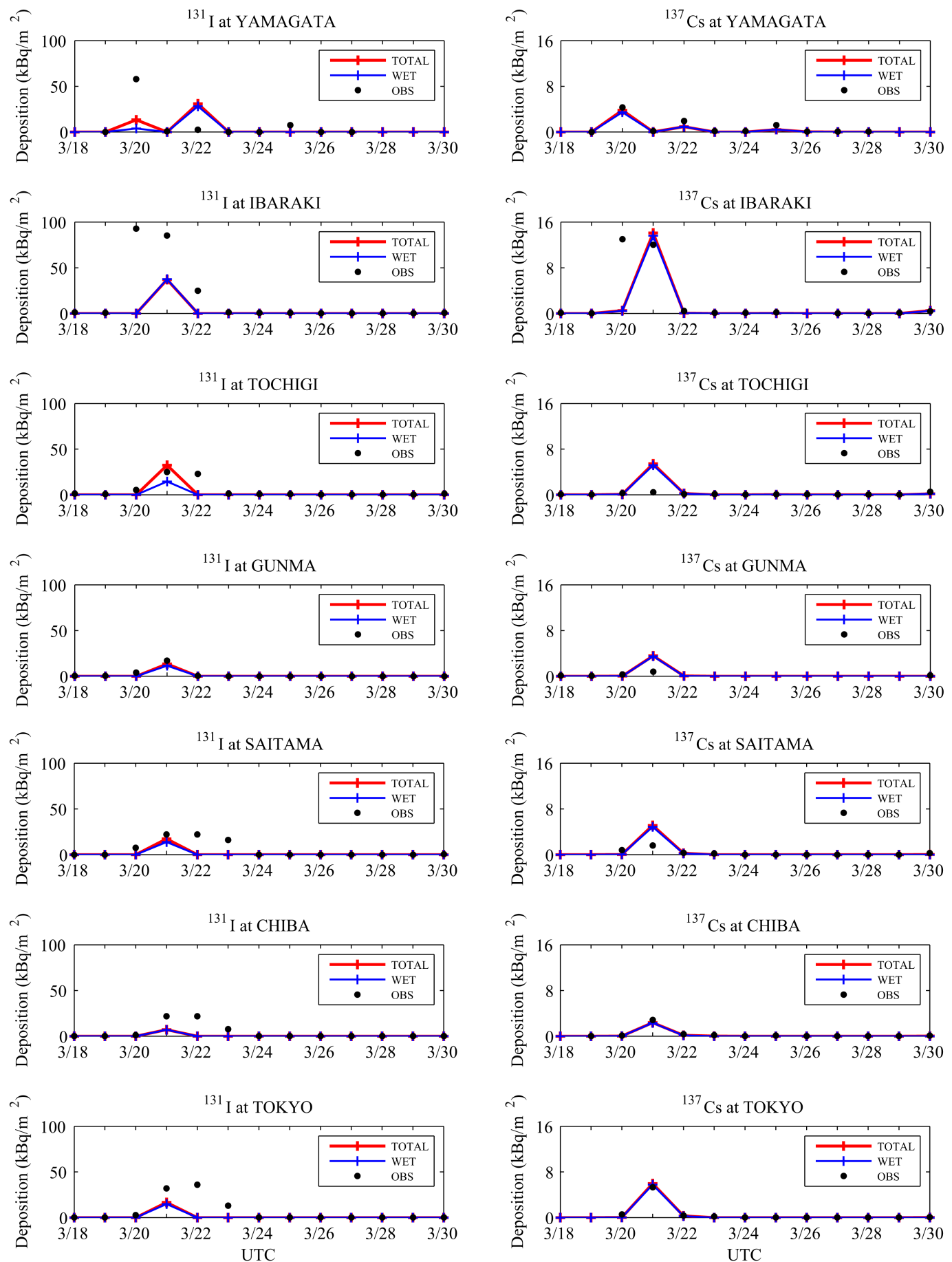

Figure 9. The comparison between simulated (REF case) total daily depositions and the observed data of ${ }^{131} \mathrm{I}$ and ${ }^{137} \mathrm{Cs}$.

wet deposition and dry deposition) have comparable influences on the results. This is because their relative contributions to the total deposition are comparable, as can be seen from Fig. 9.

The PBIAS and PRMSE of total daily depositions of ${ }^{131} \mathrm{I}$ and ${ }^{137} \mathrm{Cs}$ with different dry and wet deposition parameteri- zations are shown in Table 6 and Table 7, respectively. The PBIAS and PRMSE in REF, DRY2 and DRY3 are quite similar, suggesting that the total daily deposition for this accident is not sensitive to the choice of the dry deposition scheme, again we reiterate that this can be different for other cases where the dry deposition contributes a larger fraction of the 

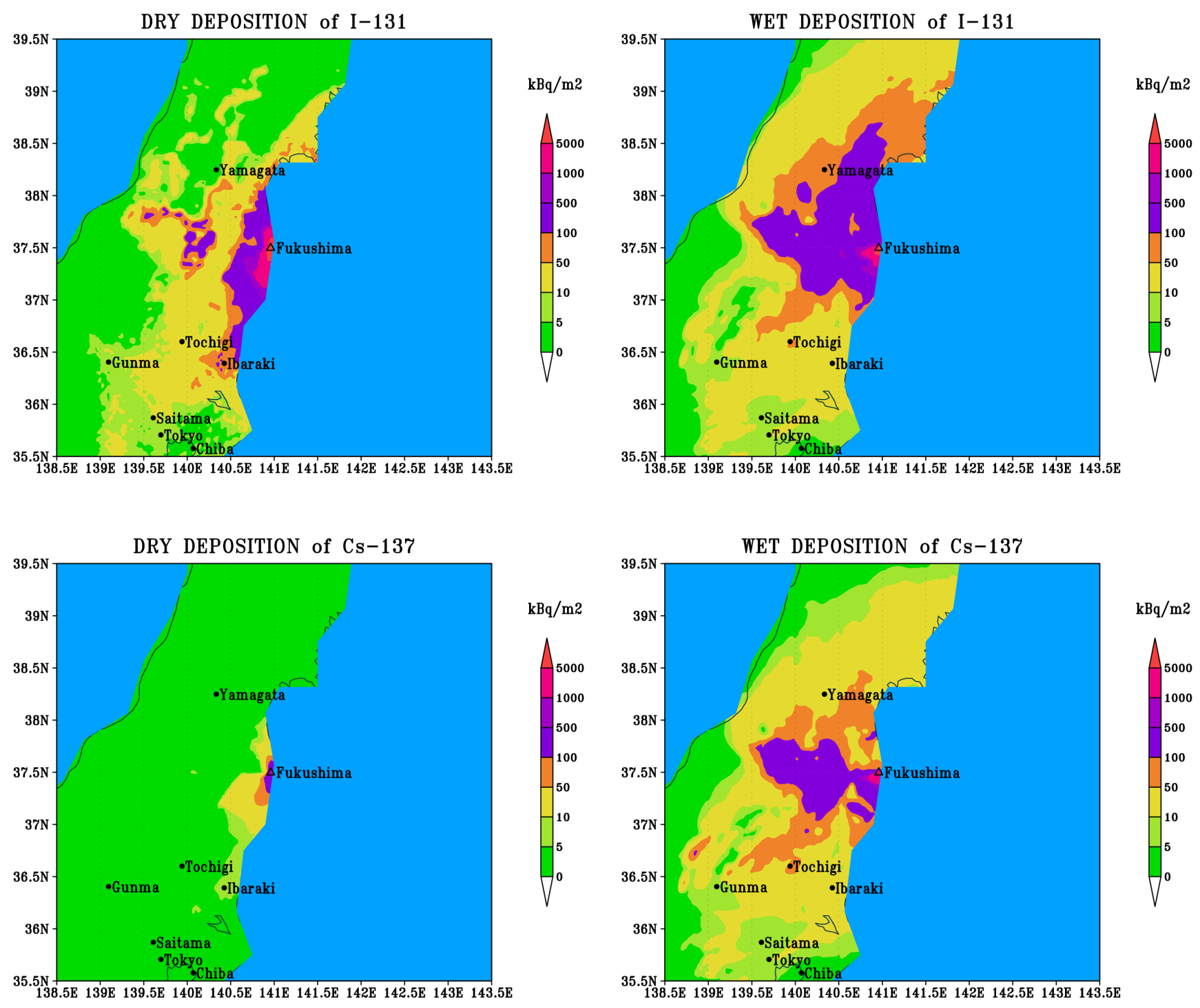

Figure 10. Distribution of accumulated dry and wet depositions of ${ }^{131} \mathrm{I}$ and ${ }^{137} \mathrm{Cs}$ over domain 2 in the reference case (REF) from 11 to 31 March. The upper panels show the accumulated dry and wet deposition of ${ }^{131} \mathrm{I}$; the area with dry deposition over $100 \mathrm{kBq} \mathrm{m}^{-2}$ is concentrated near the source and is much smaller than the area with wet deposition over $100 \mathrm{kBq} \mathrm{m}^{-2}$. The lower panels show the accumulated dry and wet deposition of ${ }^{137} \mathrm{Cs}$, the pattern of dry deposition is quite different from that of ${ }^{131} \mathrm{I}$ and most of the areas have values lower than $5 \mathrm{kBq} \mathrm{m}^{-2}$.

total deposition. This is in agreement with Fig. 11. To select the "best" dry deposition scheme, the sum of global rank (SR) is compared. Case REF and Case DRY2 have the lowest SR for ${ }^{131}$ I while case DRY3 has the lowest SR for ${ }^{137} \mathrm{Cs}$, indicating that the resistance method and the simple parameterization have the best performance in capturing the total deposition of ${ }^{131} \mathrm{I}$. Note the gas partitioning of ${ }^{131} \mathrm{I}$ at the source is chosen to be $80 \%$ as recommended by several studies and changing this value may alter our results. The method with a constant dry deposition velocity $\left(0.05 \mathrm{~cm} \mathrm{~s}^{-1}\right)$ has the best performance in capturing the total deposition of ${ }^{137} \mathrm{Cs}$, which essentially precludes making any robust inferences or recommendation about the choice of the optimal dry deposition model.

The PBIAS and PRMSE in case WET2 are of the same magnitude over most of stations as those in case REF. As for ${ }^{131}$ I, case REF has the lowest SR; while for ${ }^{137} \mathrm{Cs}$, case WET2 has the lowest SR. These results suggest that using the wet deposition parameterization based on precipitation rate can predict the total daily deposition of ${ }^{131} \mathrm{I}$ better, while for capturing the total daily deposition of ${ }^{137} \mathrm{Cs}$, using the wet deposition parameterizations based on relative humidity has a better performance. 

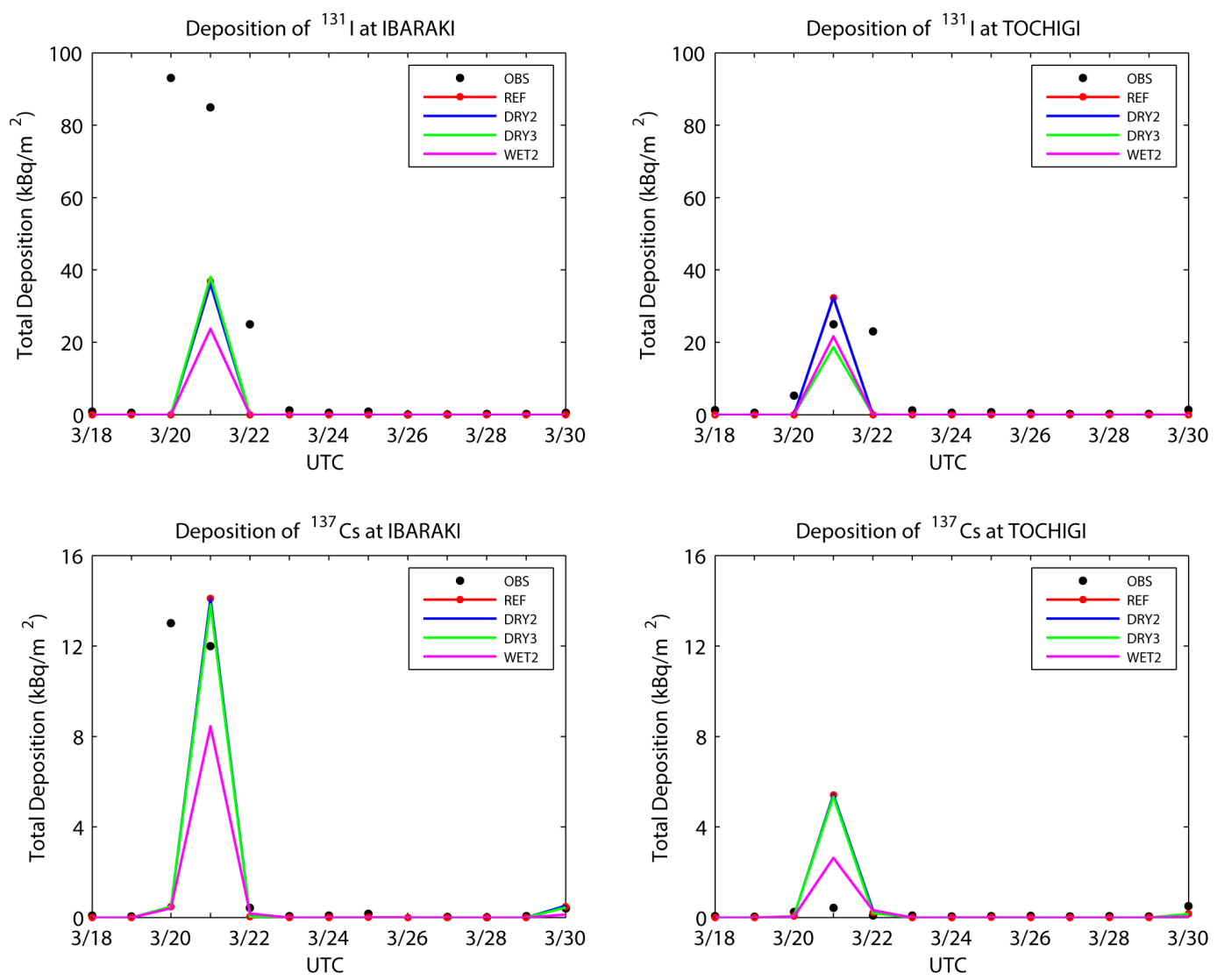

Figure 11. Daily total depositions in station IBARAKI and TOCHIGI with different dry and wet parameterizations.

Table 6. The PBIAS and PRMSE of total daily depositions of ${ }^{131} \mathrm{I}$ and ${ }^{137} \mathrm{Cs}$ with different dry deposition schemes. GR represents the global ranks for PBIAS or PRMSE, and SR represents for the sum of the global ranks. The definition of GR and SR is shown in Sect. 3.1.2. "YA", "IB", "TOC", "GU”, "SA", "CH" and "TOK" represent the stations "YAMAGATA", "IBARAKI", "TOCHIGI", "GUNMA", "SAITAMA", "CHIBA" and "TOKYO", respectively.

\begin{tabular}{llrrrrrrrrr}
\hline Errors & Cases & YA & IB & TOC & GU & SA & CH & TOK & GR & SR \\
\hline PBIAS & REF & $-36 \%$ & $-82 \%$ & $-46 \%$ & $-39 \%$ & $-75 \%$ & $-87 \%$ & $-80 \%$ & 7 & 16 \\
of ${ }^{131}$ I & DRY2 & $-36 \%$ & $-82 \%$ & $-46 \%$ & $-39 \%$ & $-75 \%$ & $-87 \%$ & $-80 \%$ & 7 & 16 \\
& DRY3 & $-50 \%$ & $-82 \%$ & $-69 \%$ & $-45 \%$ & $-79 \%$ & $-87 \%$ & $-82 \%$ & 17 & 28 \\
\hline PRMSE & REF & $235 \%$ & $187 \%$ & $149 \%$ & $87 \%$ & $151 \%$ & $187 \%$ & $176 \%$ & 9 & 16 \\
of ${ }^{131} \mathrm{I}$ & DRY2 & $235 \%$ & $187 \%$ & $149 \%$ & $87 \%$ & $151 \%$ & $187 \%$ & $176 \%$ & 9 & 16 \\
& DRY3 & $257 \%$ & $186 \%$ & $148 \%$ & $104 \%$ & $155 \%$ & $187 \%$ & $179 \%$ & 11 & 28 \\
\hline PBIAS & REF & $-36 \%$ & $-43 \%$ & $218 \%$ & $157 \%$ & $65 \%$ & $-34 \%$ & $-5 \%$ & 11 & 26 \\
of ${ }^{137} \mathrm{Cs}$ & DRY2 & $-36 \%$ & $-43 \%$ & $217 \%$ & $157 \%$ & $65 \%$ & $-34 \%$ & $-5 \%$ & 10 & 22 \\
& DRY3 & $-39 \%$ & $-44 \%$ & $212 \%$ & $153 \%$ & $59 \%$ & $-35 \%$ & $-7 \%$ & 11 & 20 \\
\hline PRMSE & REF & $55 \%$ & $167 \%$ & $977 \%$ & $452 \%$ & $369 \%$ & $52 \%$ & $44 \%$ & 15 & 26 \\
of ${ }^{137} \mathrm{Cs}$ & DRY2 & $55 \%$ & $167 \%$ & $974 \%$ & $451 \%$ & $368 \%$ & $52 \%$ & $44 \%$ & 12 & 22 \\
& DRY3 & $59 \%$ & $166 \%$ & $963 \%$ & $442 \%$ & $353 \%$ & $55 \%$ & $40 \%$ & 9 & 20 \\
\hline
\end{tabular}


Table 7. The PBIAS and PRMSE of total daily depositions of ${ }^{131}$ I and ${ }^{137}$ Cs with different wet deposition schemes. GR represents the global ranks for PBIAS or PRMSE, and SR represents for the sum of the global ranks. The definition of GR and SR is shown in Sect. 3.1.2. "YA", "IB", "TOC", "GU”, "SA", "CH" and "TOK" represent the stations "YAMAGATA", 'IBARAKI', "TOCHIGI", "GUNMA", "SAITAMA", "CHIBA" and "TOKYO", respectively.

\begin{tabular}{llrrrrrrrrr}
\hline Errors & Cases & YA & IB & TOC & GU & SA & CH & TOK & GR & SR \\
\hline PBIAS & REF & $-36 \%$ & $-82 \%$ & $-46 \%$ & $-39 \%$ & $-75 \%$ & $-87 \%$ & $-80 \%$ & 8 & 17 \\
of ${ }^{131}$ I & WET2 & $-25 \%$ & $-89 \%$ & $-64 \%$ & $-57 \%$ & $-75 \%$ & $-91 \%$ & $-82 \%$ & 12 & 24 \\
\hline PRMSE & REF & $235 \%$ & $187 \%$ & $149 \%$ & $87 \%$ & $151 \%$ & $187 \%$ & $176 \%$ & 9 & 17 \\
of ${ }^{131} \mathrm{I}$ & WET2 & $219 \%$ & $198 \%$ & $144 \%$ & $154 \%$ & $152 \%$ & $195 \%$ & $178 \%$ & 12 & 24 \\
\hline PBIAS & REF & $-36 \%$ & $-43 \%$ & $218 \%$ & $157 \%$ & $65 \%$ & $-34 \%$ & $-5 \%$ & 12 & 22 \\
of ${ }^{137} \mathrm{Cs}$ & WET2 & $-31 \%$ & $-65 \%$ & $64 \%$ & $56 \%$ & $87 \%$ & $-30 \%$ & $3 \%$ & 9 & 20 \\
\hline PRMSE & REF & $55 \%$ & $167 \%$ & $977 \%$ & $452 \%$ & $369 \%$ & $52 \%$ & $44 \%$ & 10 & 22 \\
of ${ }^{137} \mathrm{Cs}$ & WET2 & $61 \%$ & $172 \%$ & $445 \%$ & $228 \%$ & $414 \%$ & $47 \%$ & $56 \%$ & 11 & 20 \\
\hline
\end{tabular}
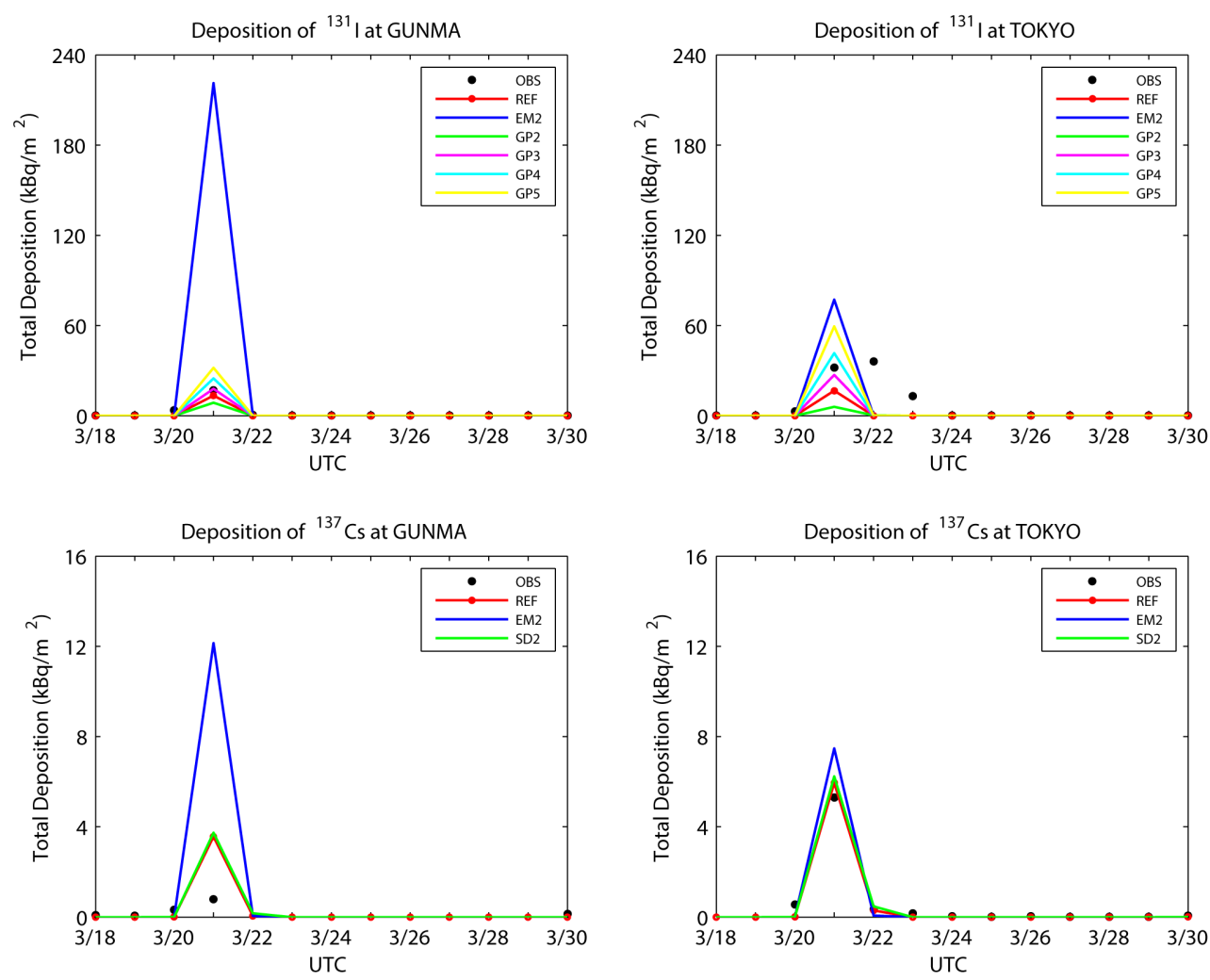

Figure 12. Daily total depositions in station GUNMA and TOKYO with different emission rates, gas partitioning of ${ }^{131}$ I and size distribution of ${ }^{137} \mathrm{Cs}$.

\subsection{The influence of emission rates and characteristics}

This section examines the sensitivity of ground deposition of ${ }^{131} \mathrm{I}$ and ${ }^{137} \mathrm{Cs}$ to the different characteristics of the emission source, including the emission rate, the gas partitioning of ${ }^{131} \mathrm{I}$, and the size distributions of ${ }^{137} \mathrm{Cs}$. Figure 12 shows the WRF-simulated and observed daily depositions of ${ }^{131} \mathrm{I}$ and ${ }^{137} \mathrm{Cs}$ at stations GUNMA and TOKYO. As can be seen in the figure, there are significant differences in the daily depositions of ${ }^{131} \mathrm{I}$ and ${ }^{137} \mathrm{Cs}$ at these two stations between the case using the emission rate estimated by JAEA and the case using emission rate estimated by TEPCO. The simulated depositions using the emission rate estimated by JAEA (REF) are lower than those from the case using emission rate estimated by TEPCO (EM2) on 19-23 March when deposition occurs at these two stations. In particular, at GUNMA, the 
deposition of ${ }^{131} \mathrm{I}$ in EM2 is about 15 times that in REF and the deposition of ${ }^{137} \mathrm{Cs}$ in EM2 is about 4 times of that in REF. Figure 13 depicts the spatial patterns of the accumulated depositions of ${ }^{131}$ I and ${ }^{137} \mathrm{Cs}$ from REF and EM2 from 11 to 31 March. For ${ }^{131} \mathrm{I}$, the area with accumulated deposition exceeding $100 \mathrm{kBq} \mathrm{m}^{-2}$ is much larger in EM2 than that in REF, covering nearly half of domain 2 over the southeast area. For ${ }^{137} \mathrm{Cs}$, in the west of FDNPP $\left(37-38^{\circ} \mathrm{N}, 139.5-\right.$ $\left.140.5^{\circ} \mathrm{E}\right), \mathrm{REF}$ produces higher depositions than EM2. The above results clearly demonstrate that the emission rates, and their temporal distributions, have a major influence on ground deposition of radionuclides. Temporal variability is important since it interacts with changes in wind speed and direction to result in the concentration maps that produce the deposition maps.

The PBIAS and PRMSE of total daily depositions of ${ }^{131} \mathrm{I}$ and ${ }^{137} \mathrm{Cs}$ with different emission rates are shown in Table 8. It is evident that the PBIAS and PRMSE of the total daily depositions of ${ }^{131} \mathrm{I}$ and ${ }^{137} \mathrm{Cs}$ in case EM2 are significantly higher than those in case REF over most of the stations, indicating that case REF better reproduces the observations. This is also reflected by the lower SR value of case REF. Morino et al. (2013) used different emission data sets in their CMAQ model simulation for the same accident and also reported that the emission rate estimated by TEPCO generally overestimated the observations, which agrees with the results reported in this paper.

In addition to emission rates, the gas partitioning of ${ }^{131} \mathrm{I}$ and the size distribution of ${ }^{137} \mathrm{Cs}$ are the two emission characteristics examined in our study. In the cases REF, GP2, GP3, GP4 and GP5, the gaseous fraction of ${ }^{131} \mathrm{I}$ is defined as $80,100,60,30$ and $0 \%$, respectively. As shown in the top panels of Fig. 12, total daily depositions of ${ }^{131} \mathrm{I}$ increase as the gaseous fraction decreases (i.e., as the fraction of particulate species increases from GP2 to GP5), which is especially prominent at the station in TOKYO. This result indicates that the total deposition of ${ }^{131} \mathrm{I}$ is sensitive to its gas partitioning at the source, which has high uncertainty (Sportisse, 2007). The fact that total daily depositions increase as the gaseous fraction decreases also suggests that for the same amount of radionuclides released from the source (these two stations are considered far from the source), more particulate species can be transported to the stations far away from the source than gaseous species. This is because that gaseous ${ }^{131} \mathrm{I}$ has a larger dry deposition velocity than particulate ${ }^{131} \mathrm{I}$; as a result, larger amounts of gaseous ${ }^{131}$ I deposit within a smaller area around the source (at least according to the deposition models used here). Hence, less gaseous ${ }^{131} \mathrm{I}$ is transported to areas that are far away from the source. Apart from that, the change in the partitioning of ${ }^{131}$ I over time is also associated with a high uncertainty, which may influence the removal rates since the gas to particle conversion of ${ }^{131}$ I typically occurs on time scales from 2 to 3 weeks (Masson, 2011).

The PBIAS and PRMSE of total deposition of ${ }^{131}$ I with different gaseous fractions are shown in Table 9. The PBIAS suggests that the GP4 case with gaseous fraction of $30 \%$ gives the best result, while the PRMSE indicates that the GP3 case with gaseous fraction of $60 \%$ yields the best result. The two cases also have very close SR values (the SR of GP4 is 28 and that of GP3 is 27). Since there were no simulations with intermediate gaseous fractions, the results can only indicate that the optimal gaseous fractions of ${ }^{131} \mathrm{I}$ lie somewhere between 30 or $60 \%$ for the model setup in this study, which is also consistent with the result from the study by Momoshima et al. (2012).

WRF-simulated total daily depositions of ${ }^{137} \mathrm{Cs}$ at the seven monitored stations using a log-normal size distribution for ${ }^{137} \mathrm{Cs}$ emission (i.e., case SD2) are compared with those using a constant particle size (i.e., case REF) in the bottom panels of Fig. 12. The results at GUNMA and TOKYO indicate that the difference between REF and SD2 is small during the period of 18-30 March. The comparisons at the other five stations show similar results (not shown here). Consequently, the total deposition of ${ }^{137} \mathrm{Cs}$ is not very sensitive to the size distribution from the comparisons at these 7 stations. This is also consistent with the study by Morino et al. (2013), in which the reference case and the sensitivity case have nearly the same errors including FAC2, FAC10 (the proportions of simulated data that reproduce the observations within a factor of 2 or 10 , respectively) and the correlation coefficient between the observed and simulated depositions.

The PBIAS and PRMSE of total deposition of ${ }^{137} \mathrm{Cs}$ with two size distributions are shown in Table 10. As can be seen, the PBIAS and PRMSE values are similar in the two cases, which is consistent with Fig. 12. The SR value in case SD2 (=20) is slightly lower than that in case REF (=22), which indicates that the case with a log-normal distribution for the size of ${ }^{137} \mathrm{Cs}$ in the emission has a slightly better performance than the case with uniform particle size of ${ }^{137} \mathrm{Cs}$.

\subsection{The assessment of the sensitivity of the total daily deposition to the model physics and inputs}

To assess the sensitivity of the total daily deposition to all of the model physics and inputs, the difference between the error in the reference case and that in specific sensitivity cases is calculated and compared. Table 11 shows the averaged absolute value of the difference (AAD) between the error in the reference case and that in different sensitivity cases (e.g., the AAD for PBIAS of ${ }^{131}$ I between REF and EM2 is $172 \%$ ). AAD is defined as follows:

$\mathrm{AAD}=\left(\sum_{i=1}^{n}\left|\operatorname{Error}_{\mathrm{REF}}-\operatorname{Error}_{\mathrm{SENS}}(i)\right|\right) / n$,

where Error $_{\mathrm{REF}}$ is the error in the reference case, Error SENS $_{\text {is }}$ the error in the specific sensitivity case, $i$ is the index of the observational station and $n$ is total number of the stations, here $n=7$.

In order to compare the sensitivity of the total daily deposition to all of the model physics and inputs, the sensitivity is divided into three groups based on AAD. If AAD $>40 \%$, 

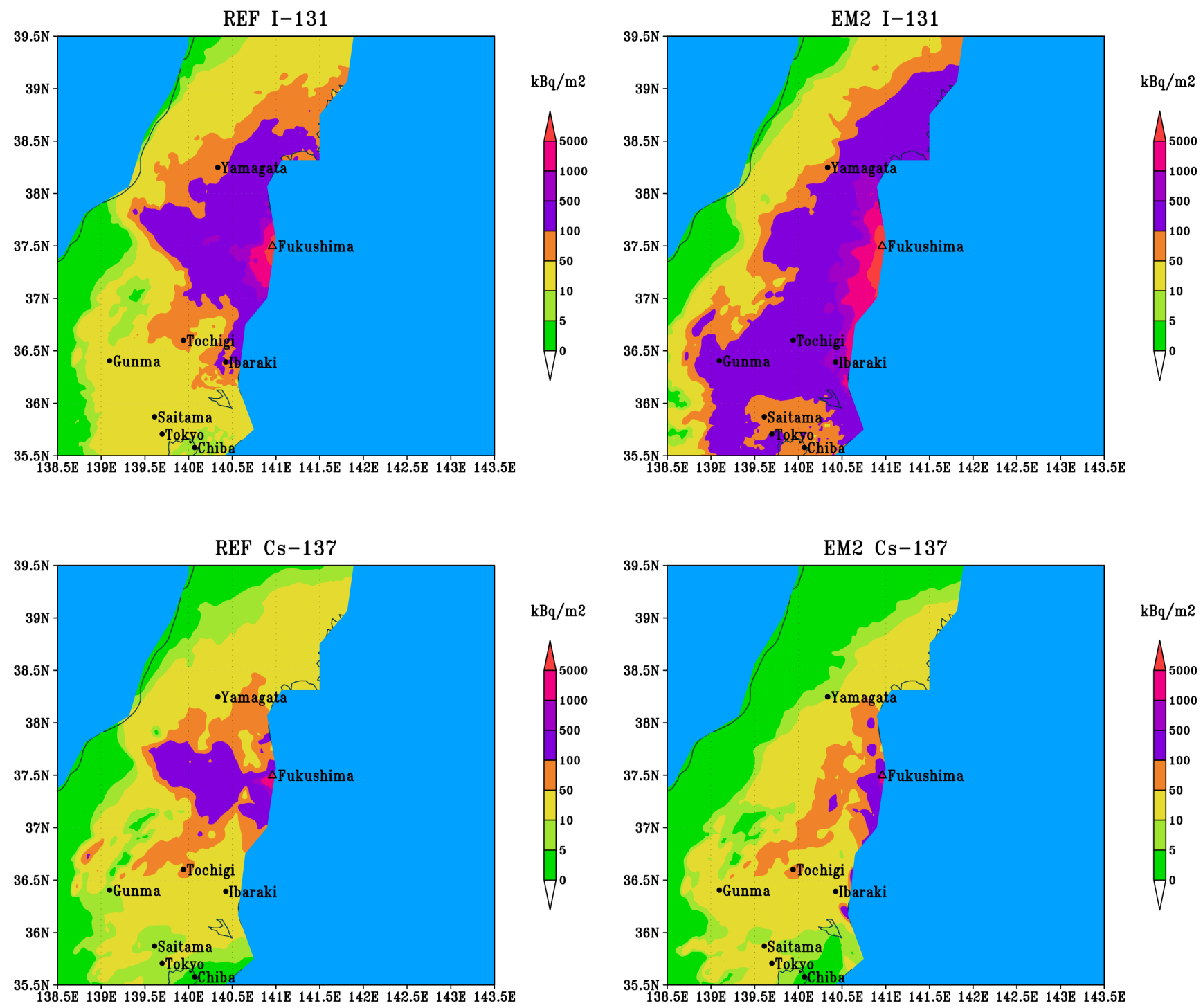

Figure 13. Distribution of accumulated total depositions of ${ }^{131} \mathrm{I}$ and ${ }^{137}$ Cs over domain 2 with different emission rates. Emission rates estimated by JAEA are used in case REF and those from TEPCO are used in case EM2.

the sensitivity is defined to "very sensitive", if AAD $>10 \%$ and $<40 \%$, the sensitivity is defined to "moderately sensitive", while if AAD $<10 \%$, the sensitivity is defined to "not sensitive".

It can be seen that the AAD in terms of both PBIAS and PRMSE for both ${ }^{131}$ I and ${ }^{137} \mathrm{Cs}$ is larger than $100 \%$ for REF (with emission estimated from JAEA) - EM2 (with emission estimated from TEPCO), thus the total daily deposition is very sensitive to the imposed emission rate. Based on AAD, we can also conclude that for ${ }^{131} \mathrm{I}$, the total daily deposition is moderately sensitive to the microphysics schemes, the horizontal diffusion schemes, gas partitioning and wet deposition parameterizations, and the total daily deposition is not sensitive to the dry deposition parameterization. For ${ }^{137} \mathrm{Cs}$, almost all of values of AAD for REF-MP2, REF-MP3 and REF-
WET2 are larger than $40 \%$, so the total daily deposition is also very sensitive to the microphysics schemes and wet deposition parameterizations, and it is moderately sensitive to the horizontal diffusion schemes and the size distribution, but it is not sensitive to the dry deposition parameterization.

\section{Conclusions}

This paper focuses on the atmospheric transport and ground deposition of radionuclides following the Fukushima Daiichi accident using the WRF-Chem model and observational data. The sensitivity of WRF-simulated results to a variety of parameters, including microphysics schemes, horizontal diffusion schemes, parameterizations for dry deposition and wet deposition, the emission rate, the gas partitioning of ${ }^{131} \mathrm{I}$, and 
Table 8. The PBIAS and PRMSE of total daily depositions of ${ }^{131} \mathrm{I}$ and ${ }^{137} \mathrm{Cs}$ with different emission rates. GR represents the global ranks for PBIAS or PRMSE, and SR represents for the sum of the global ranks. The definition of GR and SR is shown in Sect. 3.1.2. "YA", "IB", "TOC", "GU", "SA", "CH" and "TOK" represent the stations "YAMAGATA", "IBARAKI', "TOCHIGI", "GUNMA", "SAITAMA", "CHIBA" and "TOKYO", respectively.

\begin{tabular}{llrrrrrrrrr}
\hline Errors & Cases & YA & IB & TOC & GU & SA & CH & TOK & GR & SR \\
\hline PBIAS & REF & $-36 \%$ & $-82 \%$ & $-46 \%$ & $-39 \%$ & $-75 \%$ & $-87 \%$ & $-80 \%$ & 10 & 18 \\
of ${ }^{131} \mathrm{I}$ & EM2 & $-61 \%$ & $-100 \%$ & $-38 \%$ & $920 \%$ & $45 \%$ & $-87 \%$ & $-9 \%$ & 11 & 23 \\
\hline PRMSE & REF & $235 \%$ & $187 \%$ & $149 \%$ & $87 \%$ & $151 \%$ & $187 \%$ & $176 \%$ & 8 & 18 \\
of ${ }^{131} \mathrm{I}$ & EM2 & $199 \%$ & $223 \%$ & $161 \%$ & $3395 \%$ & $434 \%$ & $187 \%$ & $253 \%$ & 12 & 23 \\
\hline PBIAS & REF & $-36 \%$ & $-43 \%$ & $218 \%$ & $157 \%$ & $65 \%$ & $-34 \%$ & $-5 \%$ & 8 & 15 \\
of ${ }^{137} \mathrm{Cs}$ & EM2 & $-65 \%$ & $-81 \%$ & $204 \%$ & $775 \%$ & $128 \%$ & $-47 \%$ & $15 \%$ & 13 & 27 \\
\hline PRMSE & REF & $55 \%$ & $167 \%$ & $977 \%$ & $452 \%$ & $369 \%$ & $52 \%$ & $44 \%$ & 7 & 15 \\
of ${ }^{137} \mathrm{Cs}$ & EM2 & $148 \%$ & $192 \%$ & $1003 \%$ & $1831 \%$ & $595 \%$ & $85 \%$ & $115 \%$ & 14 & 27 \\
\hline
\end{tabular}

Table 9. The PBIAS and PRMSE of total daily depositions of ${ }^{131}$ I with different gas partitioning of ${ }^{131}$ I. GR represents the global ranks for PBIAS or PRMSE, and SR represents for the sum of the global ranks. The definition of GR and SR is shown in Sect. 3.1.2. "YA", "IB", "TOC", "GU", "SA", "CH" and "TOK" represent the stations "YAMAGATA", "IBARAKI", "TOCHIGI", "GUNMA", "SAITAMA", "CHIBA" and "TOKYO”, respectively.

\begin{tabular}{llrrrrrrrrr}
\hline Errors & Cases & YA & IB & TOC & GU & SA & CH & TOK & GR & SR \\
\hline PBIAS & REF & $-36 \%$ & $-82 \%$ & $-46 \%$ & $-39 \%$ & $-75 \%$ & $-87 \%$ & $-80 \%$ & 22 & 39 \\
of ${ }^{131} \mathrm{I}$ & GP2 & $-47 \%$ & $-93 \%$ & $-45 \%$ & $-60 \%$ & $-86 \%$ & $-96 \%$ & $-93 \%$ & 29 & 52 \\
& GP3 & $-25 \%$ & $-72 \%$ & $-44 \%$ & $-18 \%$ & $-63 \%$ & $-78 \%$ & $-68 \%$ & 14 & 27 \\
& GP4 & $7 \%$ & $-56 \%$ & $-41 \%$ & $14 \%$ & $-44 \%$ & $-62 \%$ & $-51 \%$ & 7 & 28 \\
& GP5 & $-63 \%$ & $-91 \%$ & $-79 \%$ & $-69 \%$ & $-90 \%$ & $-95 \%$ & $-93 \%$ & 33 & 63 \\
\hline PRMSE & REF & $235 \%$ & $187 \%$ & $149 \%$ & $87 \%$ & $151 \%$ & $187 \%$ & $176 \%$ & 17 & 39 \\
of ${ }^{131} \mathrm{I}$ & GP2 & $233 \%$ & $207 \%$ & $136 \%$ & $152 \%$ & $164 \%$ & $206 \%$ & $197 \%$ & 23 & 52 \\
& GP3 & $240 \%$ & $173 \%$ & $152 \%$ & $63 \%$ & $150 \%$ & $172 \%$ & $165 \%$ & 13 & 27 \\
& GP4 & $273 \%$ & $167 \%$ & $155 \%$ & $144 \%$ & $171 \%$ & $158 \%$ & $169 \%$ & 21 & 28 \\
& GP5 & $257 \%$ & $203 \%$ & $161 \%$ & $181 \%$ & $169 \%$ & $204 \%$ & $197 \%$ & 30 & 63 \\
\hline
\end{tabular}

the size distribution of ${ }^{137} \mathrm{Cs}$ in the emission is examined. The simulated meteorological fields such as wind speed, wind direction, and precipitation are evaluated by comparing to observations; the simulated total daily depositions are also compared to measurements. The percent bias (PBIAS) and percent mean square error (PRMSE) are used to assess the errors in the simulated results; the sum of the global rank (SR), which is based on the calculated PBIAS and PRMSE, is then used to identify the schemes that perform the best. The averaged absolute value of the difference (AAD) between the error in the reference case and that in different sensitivity tests is used to assess the sensitivity of the simulated total daily depositions to all model physics and inputs. If AAD $>40 \%$, the sensitivity is defined to "very sensitive", if AAD $>10 \%$ and $<40 \%$, the sensitivity is defined to "moderately sensitive", while if AAD $<10 \%$, the sensitivity is defined to "not sensitive".

The main conclusions, which are linked to questions 1 to 4 that we raise in the introduction, are as follows:
1. The wind fields are overall well reproduced by WRF. The wind speed and wind direction simulated using the Smagorinsky horizontal diffusion scheme (REF) and those using the 1.5 order TKE horizontal diffusion scheme (DIF2) yield similar results. However, the subtle differences in the wind fields still result in a significant difference in the ground deposition of radionuclides (e.g., the AAD for PRMSE of wind speed between REF and DIF2 is only $1.76 \%$ calculated based on Table 2 and Eq. (23); however, the AAD for PRMSE of the deposition of ${ }^{131}$ I between the same two simulations is $17 \%$ and that of ${ }^{137} \mathrm{Cs}$ is $36 \%$ as shown in Table 11). Based on SR, simulations using the 1.5 order TKE scheme predicted the ground deposition better than those using the horizontal Smagorinsky scheme. The averaged or the accumulated rainfall was fairly well captured by WRF, but the maximum rainfall rate was not as accurately predicted in the sensitivity cases with three different microphysics schemes (REF: WSM 6; 
Table 10. The PBIAS and PRMSE of total daily depositions of ${ }^{137} \mathrm{Cs}$ with different size distribution of ${ }^{137} \mathrm{Cs}$. GR represents the global ranks for PBIAS or PRMSE, and SR represents for the sum of the global ranks. The definition of GR and SR is shown in Sect. 3.1.2. "YA", "IB", "TOC", "GU”, "SA", "CH" and "TOK" represent the stations "YAMAGATA", "IBARAKI", "TOCHIGI", "GUNMA", "SAITAMA", "CHIBA" and "TOKYO", respectively.

\begin{tabular}{llrrrrrrrrr}
\hline Errors & Cases & YA & IB & TOC & GU & SA & CH & TOK & GR & SR \\
\hline PBIAS & REF & $-36 \%$ & $-43 \%$ & $218 \%$ & $157 \%$ & $65 \%$ & $-34 \%$ & $-5 \%$ & 12 & 22 \\
of ${ }^{137} \mathrm{Cs}$ & SD2 & $-26 \%$ & $-42 \%$ & $212 \%$ & $169 \%$ & $88 \%$ & $-18 \%$ & $3 \%$ & 9 & 20 \\
\hline PRMSE & REF & $55 \%$ & $167 \%$ & $977 \%$ & $452 \%$ & $369 \%$ & $52 \%$ & $44 \%$ & 10 & 22 \\
of ${ }^{137} \mathrm{Cs}$ & SD2 & $45 \%$ & $168 \%$ & $963 \%$ & $479 \%$ & $430 \%$ & $28 \%$ & $56 \%$ & 11 & 20 \\
\hline
\end{tabular}

Table 11. The averaged absolute value of the difference (AAD) between the error in the reference case and that in different sensitivity cases.

\begin{tabular}{lrrrr}
\hline & $\begin{array}{r}\text { AAD (PBIAS } \\
\left.\text { of }{ }^{131} \mathrm{I}\right)\end{array}$ & $\begin{array}{r}\text { AAD (PRMSE } \\
\left.\text { of }{ }^{131} \mathrm{I}\right)\end{array}$ & $\begin{array}{r}\text { AAD (PBIAS } \\
\left.\text { of }{ }^{137} \mathrm{Cs}\right)\end{array}$ & $\begin{array}{r}\text { AAD (PRMSE } \\
\left.\text { of }{ }^{137} \mathrm{Cs}\right)\end{array}$ \\
\hline REF - EM2 & $172 \%$ & $536 \%$ & $114 \%$ & $265 \%$ \\
REF - MP2 & $11 \%$ & $19 \%$ & $35 \%$ & $70 \%$ \\
REF - MP3 & $13 \%$ & $37 \%$ & $80 \%$ & $199 \%$ \\
REF - DIF2 & $6 \%$ & $17 \%$ & $16 \%$ & $36 \%$ \\
REF - GP2 & $11 \%$ & $22 \%$ & - & - \\
REF - GP3 & $11 \%$ & $10 \%$ & - & - \\
REF - GP4 & $30 \%$ & $25 \%$ & - & - \\
REF - GP5 & $19 \%$ & $28 \%$ & - & - \\
REF - SD2 & - & $0.03 \%$ & $0.20 \%$ & $0.53 \%$ \\
REF - DRY2 & $0.02 \%$ & $6.69 \%$ & $3.46 \%$ & $7.33 \%$ \\
REF - DRY3 & $7.17 \%$ & $16 \%$ & $45 \%$ & $118 \%$ \\
REF - WET2 & $9 \%$ & & & \\
\hline
\end{tabular}

MP2: Goddard; MP3: Thompson). The sensitivity of WRF simulated rain field to microphysics parameterization illustrates the difficulty in reproducing the spatial and temporal precipitation patterns as also concluded in previous studies (e.g., Li et al., 2013). The results demonstrated that the total daily deposition is very sensitive to the microphysics scheme and the WSM 6 microphysical scheme performed the best among the three schemes.

2. The simulated total daily depositions generally agreed with the pattern observed in the measurements. But the model did not estimate the observed deposition peaks and magnitudes very well for both ${ }^{131} \mathrm{I}$ and ${ }^{137} \mathrm{Cs}$. Wet deposition dominated over dry deposition at most of the observation stations, but not at all locations in the simulated domain. Moreover, the dry and wet depositions of different radionuclides are affected by wind and rainfall in different ways. Based on SR, the resistance model and the simple parameterization for dry deposition yield the best performance in capturing the total deposition of ${ }^{131} \mathrm{I}$, while the model with constant dry deposition velocity $\left(0.05 \mathrm{~cm} \mathrm{~s}^{-1}\right)$ has the best performance in capturing the total deposition of ${ }^{137} \mathrm{Cs}$. Using the wet deposition parameterization based on precipitation rate can better predict the total daily deposition of ${ }^{131} \mathrm{I}$, while using the wet deposition parameterizations based on relative humidity can better predict the total daily deposition of ${ }^{137} \mathrm{Cs}$. Again these finding could be related to differences between gaseous and particulate species.

3. The results illustrate that the total daily deposition is very sensitive to the emission rate, whose estimates by two different studies had large discrepancies. At some of the stations, the gas partitioning of ${ }^{131} \mathrm{I}$ is also an important parameters that controls the total daily deposition. The total deposition of ${ }^{137} \mathrm{Cs}$ is not very sensitive to the size distribution. Based on SR, case REF (with emission estimated from JAEA) reproduced the observations more accurately than case EM2 (with emission estimated from TEPCO); the cases with gaseous fractions of 30 or $60 \%$ had comparable performances and can better reproduce the total deposition of ${ }^{131} \mathrm{I}$ for this particular event. The case with a log-normal distribution for the size of ${ }^{137} \mathrm{Cs}$ in the emission has only a slightly better performance than the case with uniform particle size of ${ }^{137} \mathrm{Cs}$. Based on the averaged absolute value of the difference (AAD) between the error in the reference case and that in different sensitivity cases, the total deposition is most sensitive to the emission rate for both 
${ }^{131} \mathrm{I}$ and ${ }^{137} \mathrm{Cs}$, while it is not sensitive to the dry deposition parameterizations since the dry deposition is just a minor fraction of the total deposition. Moreover, based on $\mathrm{AAD}$, for ${ }^{131} \mathrm{I}$, the total daily deposition is moderately sensitive to the microphysics schemes, the horizontal diffusion schemes, gas-partitioning and wet deposition parameterizations. For ${ }^{137} \mathrm{Cs}$, the total daily deposition is also very sensitive to the microphysics schemes and wet deposition parameterizations, and it is moderately sensitive to the horizontal diffusion schemes and the size distribution.

4. While the analysis allowed us to assess the important physics schemes and inputs that significantly influenced model performance and to provide conclusions about what model options and inputs seem to produce better outputs, general conclusions about the best model configuration are difficult to make due the potential error cancellation between different options and due to fact that for some cases the best configuration or input seem to vary from one station to another. Despite this inherent uncertainty, it is clear that WRF-Chem is generally able to produce realistic deposition patterns and values, and that temporal errors in the deposition partially cancel out as evidenced by the lower values of the PBIAS compared to PRMSE. Moreover, in many cases, simulations with different options bracket the observation. As such, while it seems the uncertainty in inputs and configuration precludes very high accuracy in simulations of ground deposition, ensemble simulations with different options and a focus on accumulated deposition should prove useful in environmental impact assessments for past or potential future accidents.
Finally, the current study has some limitations that the reader needs to bear in mind when using the findings in other studies. First, changes during the transport and deposition processes of the proportion of organic and inorganic forms and of the gas partitioning and the particle size distributions were not considered in this study due to the limited knowledge of these processes, though they may strongly affect the transport and deposition of radionuclides. Second, a longer term assessment of the fate and transport of ${ }^{137} \mathrm{Cs}$ is not conducted in this study, but it may be required for assessing the heath and ecological impacts of the radionuclides release since ${ }^{137} \mathrm{Cs}$ has a very long half-life ( 30 years $)$. Future work involving idealized cases to examine in more detail how weather conditions affect the atmospheric transport and ground deposition of radionuclides is needed since out results confirm that slight modifications in the wind fields and precipitation can significantly influence deposition. 


\section{Appendix A: The improvement to WRF-Chem}

In this paper, WRF-Chem is used to simulate the atmospheric transport and ground deposition of radionuclides. The default WRF-Chem model has no radionuclides; to implement the radionuclides into WRF-Chem, we add a new chemistry package to the registry file registry.chem to include air concentration variables (in the chem array), ground deposition variables (in the misc array) and variables related to the emissions (in the emis_ant array) of ${ }^{131} \mathrm{I}$ and ${ }^{137} \mathrm{Cs}$. Moreover, several modules in the chem subdirectory are modified to account for new transport and deposition mechanisms. The radioactive decay process is added into the advection-diffusion solver. Dry deposition parameterizations for gaseous species are added into the module_dep_simple; while dry deposition parameterizations for particulate species are added into the module_gocart_drydep. Wet deposition parameterizations are added into the module_wetscav_driver. The emission rates used by the simulations are imported by the program prep_chem_sources. 
Acknowledgements. This work was supported by the Ministry of Science and Technology of the People's Republic of China under 863 (Grant no. 2012AA050907), the National Nature Science Foundation of China (Grant no. 71373140), the State Key Laboratory of NBC Protection for Civilian (no. SKLNBC0308), the Independent Research Program of Tsinghua University (2012Z10137, 2012THZ0124) and the Scientific Research Foundation for the Returned Overseas Chinese Scholars of the State Education Ministry. E. Bou-Zeid and D. Li, and the 1-year exchange visit of $\mathrm{X}$. Hu to Princeton University, are partially supported by a grant from an anonymous donor aimed at studying anthropogenic impacts on the hydrological cycle and water resources in China. We are grateful to Maofeng Liu for helping us to process the figures and Ting Sun for providing the forcing data used in the simulations.

Edited by: A. Nenes

\section{References}

Andronopoulos, S. and Bartzis, J. G.: A gamma radiation dose calculation method for use with Lagrangian puff atmospheric dispersion models used in real-time emergency response systems, J. Radiol. Prot., 30, 747-759, doi:10.1088/0952-4746/30/4/008, 2010

Baklanov, A. and Sorensen, J. H.: Parameterisation of radionuclide deposition in atmospheric long-range transport modelling, Phys. Chem. Earth Pt. B, 26, 787-799, doi:10.1016/S14641909(01)00087-9, 2001.

Basit, A., Espinosa, F., Avila, R., Raza, S., and Irfan, N.: Simulation of atmospheric dispersion of radionuclides using an EulerianLagrangian modelling system, J. Radiol. Prot., 28, 539-561, doi:10.1088/0952-4746/28/4/007, 2008.

Brandt, J., Christensen, J. H., and Frohn, L. M.: Modelling transport and deposition of caesium and iodine from the Chernobyl accident using the DREAM model, Atmos. Chem. Phys., 2, 397-417, doi:10.5194/acp-2-397-2002, 2002.

Chamberlain, A. C.: Radioactive aerosols, Cambridge environmental chemistry series, 3, Cambridge University Press, Cambridge England, New York, 255 pp., 1991.

Chino, M., Nakayama, H., Nagai, H., Terada, H., Katata, G., and Yamazawa, H.: Preliminary Estimation of Release Amounts of I-131 and Cs-137 Accidentally Discharged from the Fukushima Daiichi Nuclear Power Plant into the Atmosphere, J. Nucl. Sci. Technol., 48, 1129-1134, 2011.

Clark, M. J. and Smith, F. B.: Wet and Dry Deposition of Chernobyl Releases, Nature, 332, 245-249, doi:10.1038/332245a0, 1988.

de Sampaio, P. A. B., Junior, M. A. G., and Lapa, C. M. F.: A CFD approach to the atmospheric dispersion of radionuclides in the vicinity of NPPs, Nucl. Eng. Des., 238, 250-273, doi:10.1016/j.nucengdes.2007.05.009, 2008.

Grell, G. A., Peckham, S. E., Schmitz, R., McKeen, S. A., Frost, G., Skamarock, W. C., and Eder, B.: Fully coupled "online" chemistry within the WRF model, Atmos. Environ., 39, 6957-6975, doi:10.1016/j.atmosenv.2005.04.027, 2005.

Huh, C. A., Hsu, S. C., and Lin, C. Y.: Fukushima-derived fission nuclides monitored around Taiwan: Free tropospheric versus boundary layer transport, Earth Planet. Sc. Lett., 319, 9-14, doi:10.1016/j.eps1.2011.12.004, 2012.
Huh, C. A., Lin, C. Y., and Hsu, S. C.: Regional Dispersal of Fukushima-Derived Fission Nuclides by East-Asian Monsoon: A Synthesis and Review, Aerosol Air Qual. Res., 13, 537-544, doi:10.4209/aaqr.2012.08.0223, 2013.

IAEA: Generic models for use in assessing the impact of discharges of radioactive substances to the environment.International atomic energy agency, Vienna, 2001.

Jylha, K.: Empirical Scavenging Coefficients of Radioactive Substances Released from Chernobyl, Atmos. Environ. A-Gen., 25 , 263-270, doi:10.1016/0960-1686(91)90297-K, 1991.

Kaneyasu, N., Ohashi, H., Suzuki, F., Okuda, T., and Ikemori, F.: Sulfate Aerosol as a Potential Transport Medium of Radiocesium from the Fukushima Nuclear Accident, Environ. Sci. Technol., 46, 5720-5726, doi:10.1021/Es204667h, 2012.

Katata, G., Ota, M., Terada, H., Chino, M., and Nagai, H.: Atmospheric discharge and dispersion of radionuclides during the Fukushima Dai-ichi Nuclear Power Plant accident. Part I: Source term estimation and local-scale atmospheric dispersion in early phase of the accident, J. Environ. Radioactiv., 109, 103-113, doi:10.1016/j.jenvrad.2012.02.006, 2012.

Korsakissok, I., Mathieu, A., and Didier, D.: Atmospheric dispersion and ground deposition induced by the Fukushima Nuclear Power Plant accident: A local-scale simulation and sensitivity study, Atmos. Environ., 70, 267-279, doi:10.1016/j.atmosenv.2013.01.002, 2013.

Lauritzen, B., Baklanov, A., Mahura, A., Mikkelsen, T., and Sorensen, J. H.: Probabilistic risk assessment for long-range atmospheric transport of radionuclides, J. Environ. Radioactiv., 96, 110-115, doi:10.1016/j.jenvrad.2007.01.026, 2007.

Leelossy, A., Meszaros, R., and Lagzi, I.: Short and long term dispersion patterns of radionuclides in the atmosphere around the Fukushima Nuclear Power Plant, J. Environ. Radioactiv., 102, 1117-1121, doi:10.1016/j.jenvrad.2011.07.010, 2011.

Li, D., Bou-Zeid, E., Baeck, M. L., Jessup, S., and Smith, J. A.: Modeling land surface processes and heavy rainfall in urban environments: sensitivity to urban surface representations, J. Hydrometeorol., 14, 1098-1118, doi:10.1175/JHM-D-12-0154.1, 2013.

Lutman, E. R., Jones, S. R., Hill, R. A., McDonald, P., and Lambers, B.: Comparison between the predictions of a Gaussian plume model and a Lagrangian particle dispersion model for annual average calculations of long-range dispersion of radionuclides, J. Environ. Radioactiv., 75, 339-355, doi:10.1016/j.jenvrad.2003.11.013, 2004.

Maryon, R. H., Smith, F. B., Conway, B. J., and Goddard, D. M.: The Uk Nuclear Accident Model, Prog. Nucl. Energ., 26, 85104, doi:10.1016/0149-1970(91)90043-O, 1991.

Masson, O. E. A.: Tracking of Airborne Radionuclides from the Damaged Fukushima Dai-Ichi Nuclear Reactors by European Networks, Environ. Sci. Technol., 45, 7670-7677, doi:10.1021/Es2017158, 2011.

Masson, O. E. A.: Size distributions of airborne radionuclides from the Fukushima nuclear accident at several places in Europe, Environ. Sci. Technol., 47, 10995-1003, doi:10.1021/Es401973c, 2013.

Mathieu, A., Korsakissok, I., Quelo, D., Groell, J., Tombette, M., Didler, D., Quentric, E., Saunier, O., Benoit, J. P., and Isnard, O.: Atmospheric Dispersion and Deposition of Radionuclides from 
the Fukushima Daiichi Nuclear Power Plant Accident, Elements, 8, 195-200, doi:10.2113/gselements.8.3.195, 2012.

Momoshima, N., Sugihara, S., Ichikawa, R., and Yokoyama, H.: Atmospheric radionuclides transported to Fukuoka, Japan remote from the Fukushima Dai-ichi nuclear power complex following the nuclear accident, J. Environ. Radioactiv., 111, 28-32, doi:10.1016/j.jenvrad.2011.09.001, 2012.

Morino, Y., Ohara, T., and Nishizawa, M.: Atmospheric behavior, deposition, and budget of radioactive materials from the Fukushima Daiichi nuclear power plant in March 2011, Geophys. Res. Lett., 38, L00G11, doi:10.1029/2011g1048689, 2011.

Morino, Y., Ohara, T., Watanabe, M., Hayashi, S., and Nishizawa, M.: Episode Analysis of Deposition of Radiocesium from the Fukushima Daiichi Nuclear Power Plant Accident, Environ. Sci. Technol., 47, 2314-2322, doi:10.1021/Es304620x, 2013.

Pudykiewicz, J.: Simulation of the Chernobyl dispersion with a 3-D hemispheric tracer model, Tellus B, 41, 391-412, doi:10.1111/j.1600-0889.1989.tb00317.x, 1989.

Ristovski, Z. D., Fletcher, C., D’Anna, B., Johnson, G. R., and Bostrom, J. T.: Characterization of iodine particles with Volatilization-Humidification Tandem Differential Mobility Analyser (VH-TDMA), Raman and SEM techniques, Atmos. Chem. Phys. Discuss., 6, 1481-1508, doi:10.5194/acpd-6-14812006, 2006.

Seinfeld, J. H. and Pandis, S. N.: Atmospheric chemistry and physics : from air pollution to climate change, 2nd Edn., John Wiley \& Sons, Inc., Hoboken, New Jersey, 1203 pp., 2006.

Sportisse, B.: A review of parameterizations for modelling dry deposition and scavenging of radionuclides, Atmos. Environ., 41, 2683-2698, doi:10.1016/j.atmosenv.2006.11.057, 2007.

Srinivas, C. V., Venkatesan, R., Baskaran, R., Rajagopal, V., and Venkatraman, B.: Regional scale atmospheric dispersion simulation of accidental releases of radionuclides from Fukushima Dai-ichi reactor, Atmos. Environ., 61, 66-84, doi:10.1016/j.atmosenv.2012.06.082, 2012.

Stohl, A., Seibert, P., Wotawa, G., Arnold, D., Burkhart, J. F., Eckhardt, S., Tapia, C., Vargas, A., and Yasunari, T. J.: Xenon133 and caesium-137 releases into the atmosphere from the Fukushima Dai-ichi nuclear power plant: determination of the source term, atmospheric dispersion, and deposition, Atmos. Chem. Phys., 12, 2313-2343, doi:10.5194/acp-12-2313-2012, 2012.

Stull, R. B.: An introduction to boundary layer meteorology, Atmospheric sciences library, Kluwer Academic Publishers, Dordrecht, Boston, 666 pp., 1988.
Takemura, T., Nakamura, H., Takigawa, M., Kondo, H., Satomura, T., Miyasaka, T., and Nakajima, T.: A Numerical Simulation of Global Transport of Atmospheric Particles Emitted from the Fukushima Daiichi Nuclear Power Plant, Sola, 7, 101-104, doi:10.2151/sola.2011-026, 2011.

Talbot, C., Bou-Zeid, E., and Smith, J.: Nested Mesoscale LargeEddy Simulations with WRF: Performance in Real Test Cases, J. Hydrometeorol., 13, 1421-1441, doi:10.1175/Jhm-D-11-048.1, 2012.

Ten Hoeve, J. E. and Jacobson, M. Z.: Worldwide health effects of the Fukushima Daiichi nuclear accident, Energ. Environ. Sci., 5, 8743-8757, doi:10.1039/C2ee22019a, 2012.

Tepco: Estimation of Radioactive Material Released to the Atmosphere during the Fukushima Daiichi NPS Accident, available at: http://www.tepco.co.jp/en/press/corp-com/release/betu12_e/ images/120524e0205.pdf (last access: 6 April 2013), 2012.

Terada, H. and Chino, M.: Development of an Atmospheric Dispersion Model for Accidental Discharge of Radionuclides with the Function of Simultaneous Prediction for Multiple Domains and its Evaluation by Application to the Chernobyl Nuclear Accident, J. Nucl. Sci. Technol., 45, 920-931, doi:10.3327/Jnst.45.920, 2008.

Terada, H., Katata, G., Chino, M., and Nagai, H.: Atmospheric discharge and dispersion of radionuclides during the Fukushima Dai-ichi Nuclear Power Plant accident. Part II: verification of the source term and analysis of regional-scale atmospheric dispersion, J. Environ. Radioactiv., 112, 141-154, doi:10.1016/j.jenvrad.2012.05.023, 2012.

Till, J. E. and Grogan, H. A.: Radiological risk assessment and environmental analysis, Oxford University Press, Oxford, New York, 702 pp., 2008.

Weast, R. C.: CRC handbook of chemistry and physics, 1st Student Edn., CRC Press, Boca Raton, FL, 1988.

Wesely, M. L.: Parameterization of Surface Resistances to Gaseous Dry Deposition in Regional-Scale Numerical-Models, Atmos. Environ., 23, 1293-1304, doi:10.1016/0004-6981(89)90153-4, 1989.

Yamauchi, M.: Secondary wind transport of radioactive materials after the Fukushima accident, Earth Planets Space, 64, E1-E4, doi:10.5047/eps.2012.01.002, 2012.

Yasunari, T. J., Stohl, A., Hayano, R. S., Burkhart, J. F., Eckhardt, S., and Yasunari, T.: Cesium-137 deposition and contamination of Japanese soils due to the Fukushima nuclear accident, P. Natl. Acad. Sci. USA, 108, 19530-19534, doi:10.1073/pnas.1112058108, 2011.

Zakaib, G. D.: Radiation risks unknown, Nature, 471, 419-419, 2011. 